\title{
Redundancy and modularity in membrane-associated dissimilatory nitrate reduction in Bacillus
}

\author{
Kim Heylen ${ }^{1 *}$ and Jan Keltjens ${ }^{2}$ \\ 1 Laboratory of Microbiology, Department of Biochemistry and Microbiology, University of Ghent, Gent, Belgium \\ 2 Department of Microbiology, IWWR, Radboud University Nijmegen, Nijmegen, Netherlands
}

\section{Edited by:}

Boran Kartal, Radboud University,

Netherlands

Reviewed by:

Evelyn Toh, Indiana University

Bloomington, USA

Lisa Y. Stein, University of Alberta,

Canada

Sebastian Luecker, University of

Vienna, Austria

*Correspondence:

Kim Heylen, Laboratory of Microbiology (LM-UGent),

Department of Biochemistry and

Microbiology, University of Ghent,

K.L. Ledeganckstraat 35, 9000 Gent,

Belgium.

e-mail:kim.heylen@ugent.be
The genomes of two phenotypically denitrifying type strains of the genus Bacillus were sequenced and the pathways for dissimilatory nitrate reduction were reconstructed. Results suggest that denitrification proceeds in the periplasmic space and in an analogous fashion as in Gram-negative organisms, yet with the participation of proteins that tend to be membrane-bound or membrane-associated. A considerable degree of functional redundancy was observed with marked differences between $B$. azotoformans LMG $9581^{\top}$ and $B$. bataviensis LMG $21833^{\top}$. In addition to the already characterized menaquinol/cyt c-dependent nitric oxide reductase (Suharti et al., 2001, 2004) of which the encoding genes could be identified now, evidence for another novel nitric oxide reductase (NOR) was found. Also, our analyses confirm earlier findings on branched electron transfer with both menaquinol and cytochrome $c$ as reductants. Quite unexpectedly, both bacilli have the disposal of two parallel pathways for nitrite reduction enabling a life style as a denitrifier and as an ammonifying bacterium.

Keywords: dissimilatory nitrate reduction to ammonium (DNRA), denitrification, ammonification, nitric oxide reductase

\section{INTRODUCTION}

Nitrogen is an essential element of all forms of life, but most of it on Earth is only available in an inaccessible form as dinitrogen gas $\left(\mathrm{N}_{2}\right)$. Nitrogen-fixing microorganisms, however, are able to bind $\mathrm{N}_{2}$ into ammonium, which serves as a nutrient for other organisms. Nitrifiers use ammonium as the electron donor in their energy metabolism by oxidizing it to nitrite and nitrate. The latter two compounds are utilized by other microbial species for anaerobic respiration, reducing nitrite and nitrate back to dinitrogen gas in a process called denitrification or dissimilatory nitrate/nitrite reduction, thus closing the biogeochemical nitrogen cycle (N-cycle). These three basic processes have been known for over hundred years, but in the last decades it has become clear that the $\mathrm{N}$-cycle is definitely more complex. It now appears that two major processes have been overlooked for a long time: anaerobic ammonium oxidation (anammox) and dissimilatory reduction of nitrite/nitrate into ammonium (DNRA), also known as nitrate/nitrite ammonification [see for recent reviews: Jetten (2008); Kraft et al. (2011); Lam and Kuypers (2011); MartínezEspinosa et al. (2011)]. Like classical denitrifiers, DNRA bacteria employ nitrite and nitrate as electron acceptors for respiration (Einsle et al., 2002). They, however, reduce these compounds to ammonium as the name suggests. Hitherto, no species are known that carry out both denitrification and DNRA.

In its canonical form, dissimilatory nitrate reduction consists of four consecutive steps: (1) reduction of nitrate to nitrite, (2) nitrite reduction to nitric oxide (NO), (3) NO reduction to produce nitrous oxide $\left(\mathrm{N}_{2} \mathrm{O}\right)$, and (4) reduction of the latter to $\mathrm{N}_{2}$. The specific enzyme for $\mathrm{N}_{2} \mathrm{O}$ reduction, $\mathrm{N}_{2} \mathrm{O}$ reductase (NOS, $\mathrm{N}_{2} \mathrm{OR}$ ) is not always present and microorganisms lacking this enzyme make $\mathrm{N}_{2} \mathrm{O}$ as their end product. In practice, a "true denitrifier" converts at least $80 \%$ of the consumed nitrate or nitrite to either $\mathrm{N}_{2} \mathrm{O}$ or $\mathrm{N}_{2}$ (Mahne and Tiedje, 1995). Also DNRA bacteria are capable of $\mathrm{N}_{2} \mathrm{O}$ formation, albeit in non-stoichiometric amounts that don't exceed $2-36 \%$ of consumed nitrate (Bleakley and Tiedje, 1982; Streminíska et al., 2012). Moreover, the production occurs only during the stationary phase, suggesting emission to be the result of a secondary metabolism (Smith, 1983).

The process of dissimilatory nitrate reduction has been extensively investigated at the genetic, enzymological, and regulatory levels using, among others, Paracoccus denitrificans, Pseudomonas stutzeri, Eschericha coli, and Wolinella succinogenes as model organisms [see for example: Tucker et al. (2005); van Wonderen et al. (2008); Bergaust et al. (2010); Pomowski et al. (2011); Peña et al. (2012), and references in Zumft (1997); Kern and Simon (2009); Simon and Klotz (2012)], of which most belong to Gram-negative Proteobacteria. In the Gram-negative bacteria, the enzymatic reactions involved in denitrification reside at the periplasm, except for nitrate reduction by the Nar-type nitrate reducase, and are catalyzed either by soluble enzymes (periplasmic nitrate-, nitrite-, and $\mathrm{N}_{2} \mathrm{O}$ reductases) or enzymes having their catalytic site embedded in the membrane (NO reductase). Similarly, electron transfer processes that are related to the different reduction reactions are mediated by a broad variety of soluble cytochrome $c$ type or cupredoxin-like copper proteins localized in the periplasm.

Dissimilatory nitrate reduction is not restricted to Gramnegative species. In fact, denitrification and DNRA activities have been observed in a wide species and niche diversity among Grampositive microorganisms as well, in particular Bacillus species 
(de Barjac and Bonnefoi, 1972; Garcia, 1977; Pichinoty et al., 1978, 1983; Tiedje, 1988; Denariaz et al., 1989). However, our knowledge at the molecular and genomic levels on this taxonomic lineage is rather fragmentary. Whereas many genomes of the representatives of the genus Bacillus are available, only four genomes have been reported to contain genes encoding denitrification or ammonification key enzymes. The genome of Bacillus selenitireducens was found to harbor a homolog of the gene coding for dissimilatory nitrite reductase making ammonium ( $n r f A$ ), while qnorB homologs, encoding the quinol-dependent nitric oxide reductase (NOR), were detected in Bacillus coagulans XZL4 (Su et al., 2011), Bacillus licheniformis ATCC $14580^{\mathrm{T}}$ (Rey et al., 2004; Veith et al., 2004), and Bacillus sp. BTB_CT2. None of these species can be unequivocally designated as denitrifiers. Unlike Gram-negative bacteria, Gram-positive microorganisms only have a very limited periplasmic space. In this respect, it is remarkable that activities of denitrifying enzymes were consistently associated with membrane fractions (Denariaz et al., 1991; Urata and Satoh, 1991; Suharti et al., 2001; Suharti and de Vries, 2005; Fukuda et al., 2011; Matsumoto et al., 2012). Similarly, the limited number of such enzymes that have been purified to date from bacilli or close relatives are all membrane proteins (Denariaz et al., 1991; Urata and Satoh, 1991; Suharti et al., 2001; Suharti and de Vries, 2005; Fukuda et al., 2011; Matsumoto et al., 2012).

Considering the wide-spread occurrence of dissimilatory nitrate reduction and DNRA among Bacillus species (Verbaendert et al., 2011), their ecological relevance, niche, and species differentiation, possibly particular demands that are posed to the localization and organization of enzymes involved in these processes, and an overall limited knowledge regarding their molecular mechanisms, we now sequenced the genomes of two well-known denitrifying, publicly available representatives, Bacillus azotoformans LMG 9581 ${ }^{\mathrm{T}}$ (Pichinoty et al., 1983) and Bacillus bataviensis LMG $21833^{\mathrm{T}}$ (Heyrman et al., 2004), able to produce dinitrogen and nitrous oxide respectively as end-products (Verbaendert et al., unpublished data). In order to come to a more comprehensive understanding of nitrate respiration by these Gram-positive microorganisms, we focused on their denitrifying inventories. Using bio-informatic tools, all gene products were analyzed for their homology with well studied enzymes from other organisms, their cellular localization and, in case of membrane proteins, for their putative topology and orientation. The results of our study enabled an unprecedented insight into the genomic basis underlying denitrification in both Bacillus species.

\section{MATERIALS AND METHODS STRAINS AND DNA EXTRACTION}

Bacillus azotoformans LMG $9581^{\mathrm{T}}$ and Bacillus bataviensis LMG $21833^{\mathrm{T}}$ were obtained from the BCCM/LMG bacteria collection. Strains were aerobically grown on trypticase soy broth at $28^{\circ} \mathrm{C}$. Cells were harvested after overnight growth and DNA was extracted by the method of Pitcher et al. (1989), slightly modified as described previously (Heyndrickx et al., 1996).

\section{GENOME SEQUENCING}

Library preparation and genome sequencing was performed by Baseclear B.V. For sequencing, a paired-end strategy on the
Illumina Genome Analyzer IIx was used that yielded reads of an average length of $74 \mathrm{bp}$. Automatic trimming (based on a threshold of $Q=20$ ) and assembly was performed using CLC Genomics Workbench v4. The k-mer parameter was varied to maximize the N50 of the resulting assembly for each genome. Genome statistics are listed in Table $\mathbf{1 .}$

\section{GENOME ANNOTATION}

Functional annotation and metabolic reconstruction was performed with (1) the Rapid Annotation Subsystem Technology (RAST) server (Aziz et al., 2008), using Glimmer (Salzberg et al., 1998) for gene calling and allowing frameshift correction, backfilling of gaps, and automatic fixing of errors, (2) KEGG Automatic Annotation Server (KAAS) (Moriya et al., 2007), using Glimmer gene calls from RAST and total prokaryotic genes data set for annotation, and (3) NCBI's Prokaryotic Genome Automatic Annotation Pipeline (PGAAP) (http:// www.ncbi.nlm.nih.gov/genomes/static/Pipeline.html) which uses GeneMark and GeneMark.HMM for gene calling (Borodovsky and McIninch, 1993; Lukashin and Borodovsky, 1998). Assigned functions were checked with pBLAST (Altschul et al., 1997) and InterProScan (Zdobnov and Apweiler, 2001). An inventory of genes involved in denitrification and ammonification for both genomes are listed in Tables 2, 3. Missing genes were searched for in the genome with PSI-BLAST using homologous amino acid sequences of closely related Bacillus or Geobacillus species. Possible frameshifts mentioned in the text were not corrected in the submitted genome.

Location of proteins in cells was initially predicted with sequence-based tools as described by Emanuelsson et al. (2007): SignalP 4.0 (Petersen et al., 2011) was used for prediction of secretory signal proteins, TatP 1.0 for twin-arginine translocation signal proteins (Bendtsen et al., 2005), TMHMM 2.0 for transmembrane $\alpha$-helices (Krogh et al., 2001), LipoP 1.0 (Rahman et al., 2008) for lipoprotein signal proteins, and SecretomeP 2.0 for signal peptide-less secretion (Bendtsen et al., 2004). If a transmembrane helix was predicted in the same region as a signal peptide, results were verified with Phobius (Käll et al., 2004).

Table 1 | Genome characteristics of both analyzed genomes.

\begin{tabular}{|c|c|c|}
\hline & $\begin{array}{l}\text { B. azotoformans } \\
\text { LMG } 9581^{\top}\end{array}$ & 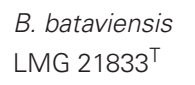 \\
\hline \# contigs & 169 & 197 \\
\hline Size (Mb) & 4,3 MB & $5,4 \mathrm{Mb}$ \\
\hline Av. read coverage & $86 x$ & $79,5 x$ \\
\hline N50 (Kb) & 94,5 & 82,1 \\
\hline$\% \mathrm{G}+\mathrm{C}$ & 39,7 & 39,6 \\
\hline \multirow[t]{2}{*}{ \# RNA calls } & 8 rRNA & 6 rRNA \\
\hline & 25 tRNA & 23 tRNA \\
\hline \# CDS calls & 4226 & 5207 \\
\hline $\mathrm{NCBI}$ accession $n^{\circ}$ & AJLR00000000 & AJLS00000000 \\
\hline NCBI BioProject & PRJNA80827 & PRJNA77725 \\
\hline
\end{tabular}

Calls for RNA and CDS were deduced from PGAAP. 
Table 2 | Overview of gene inventory involved in nitrogen assimilation, denitrification and ammonification of $B$. azotoformans LMG 9581 ${ }^{\top}$.

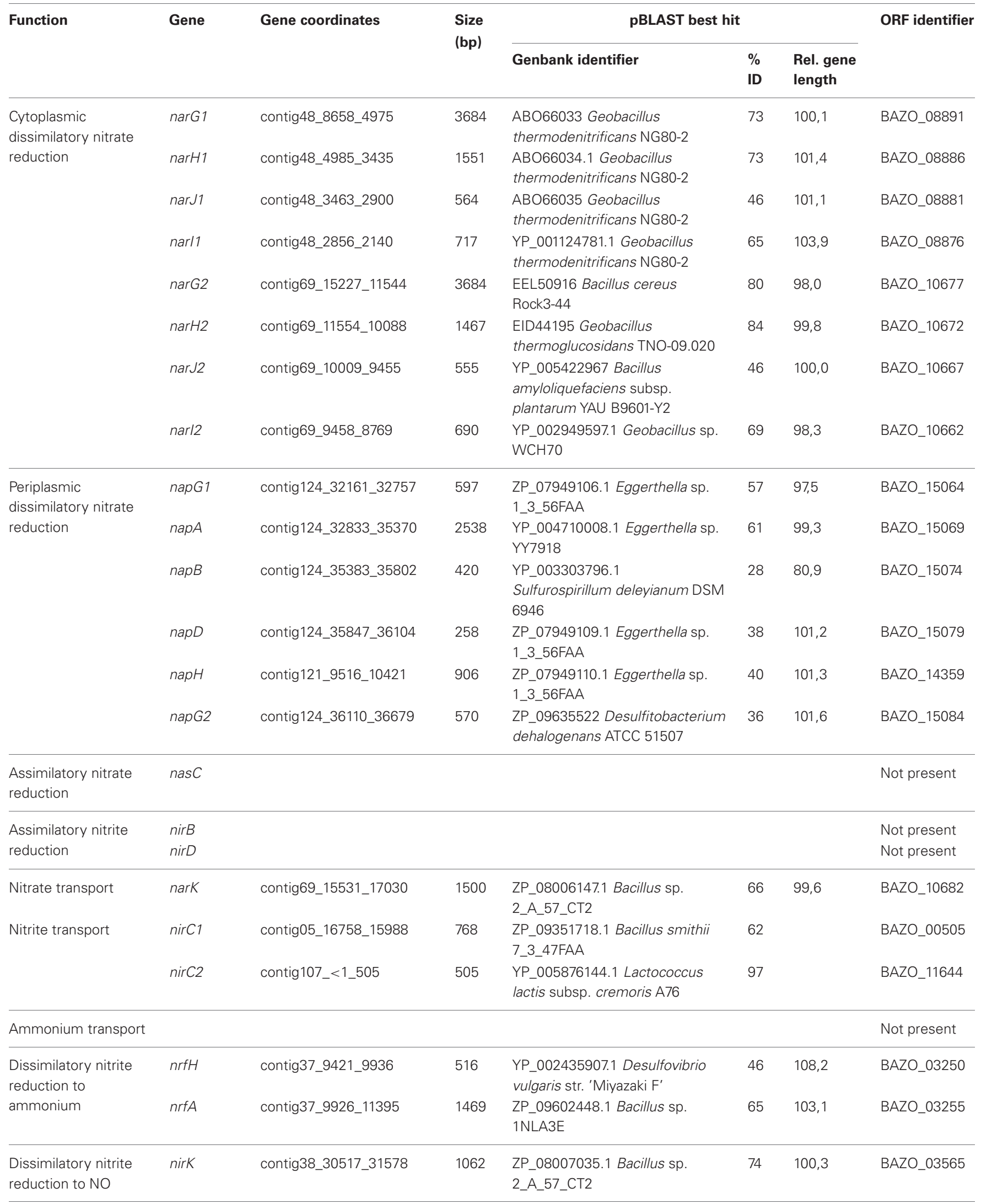


Table 2 | Continued.

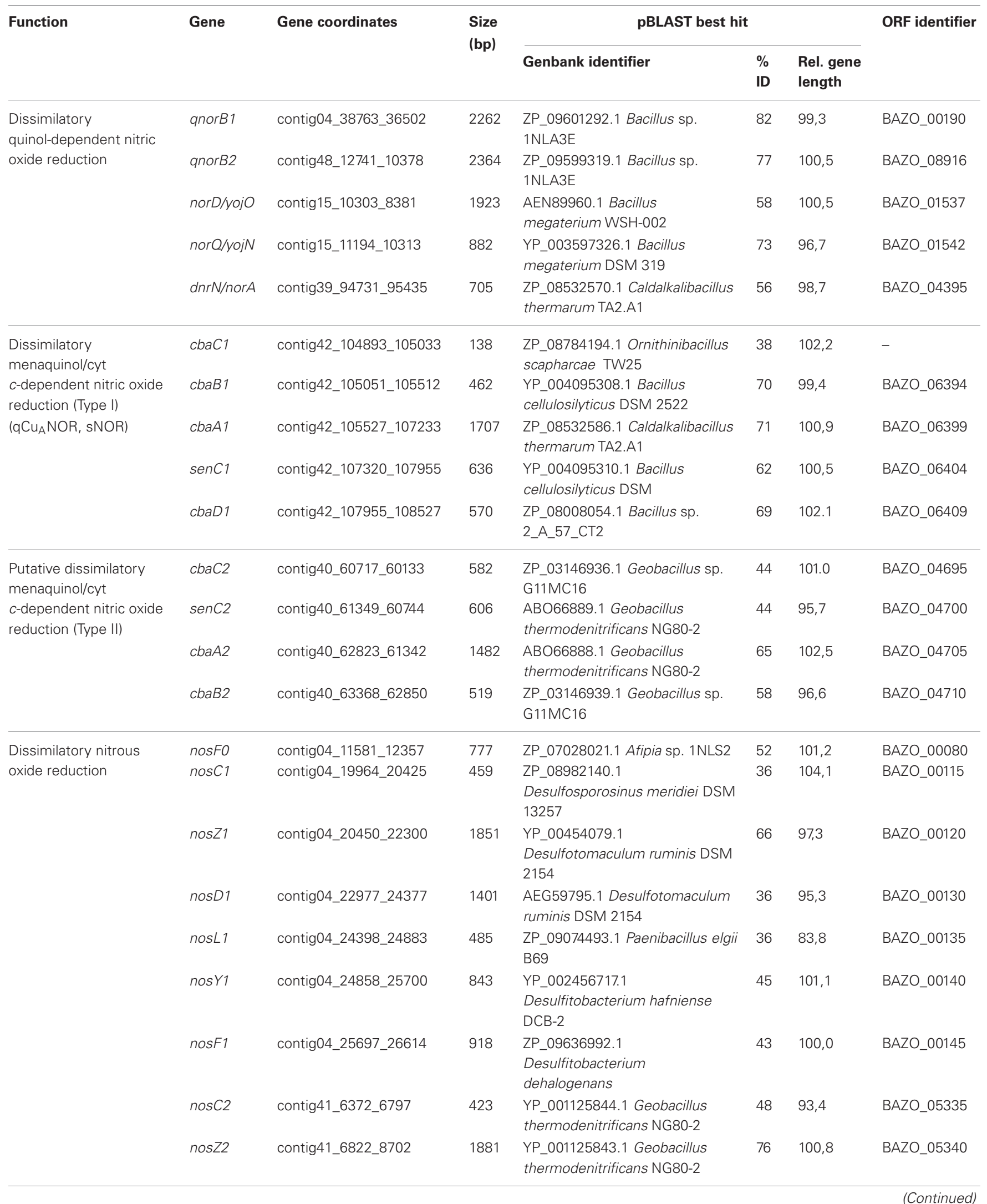


Table 2 | Continued.

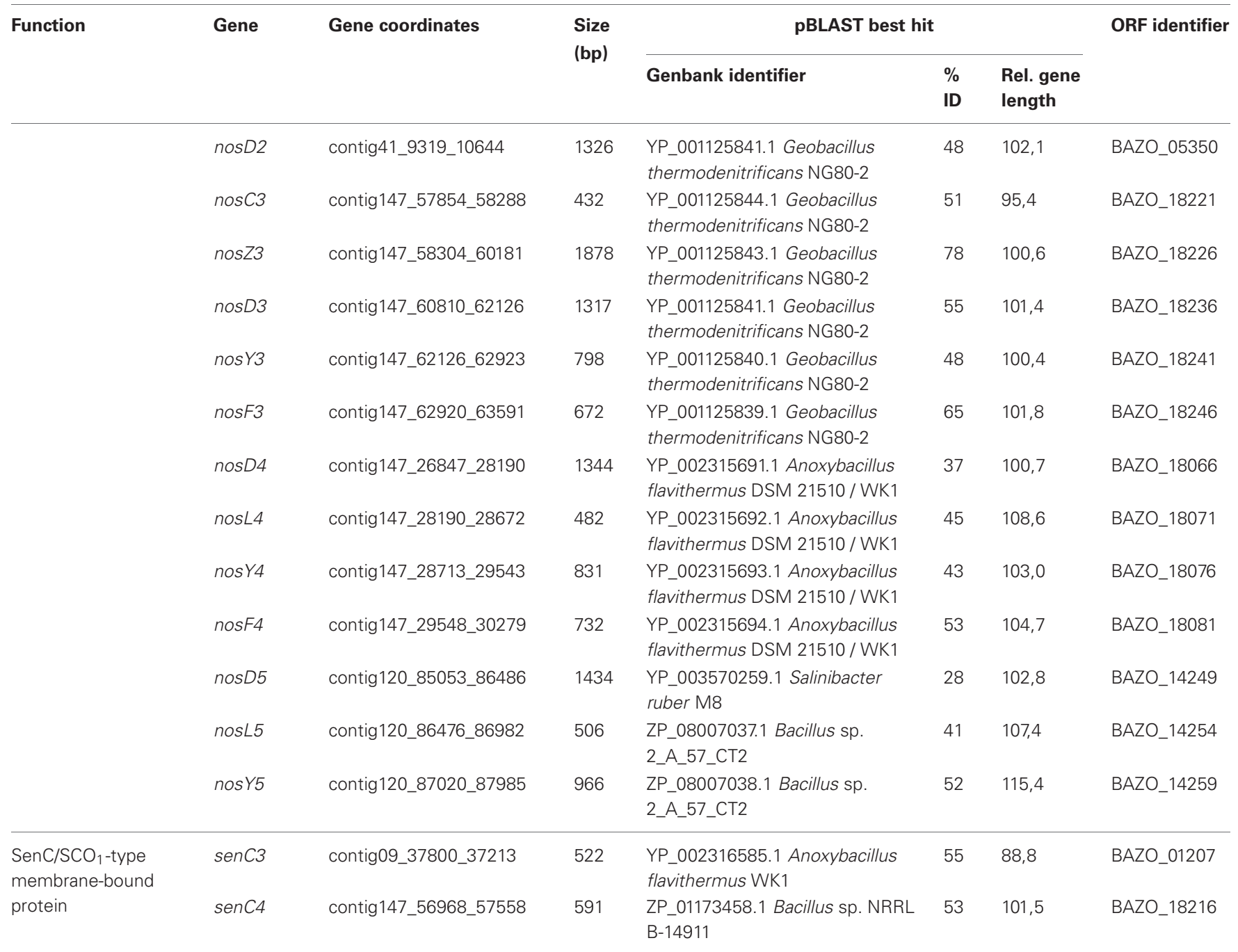

Genes are ordered according to their location in the operon when applicable. Gene size is given in absolute numbers as well as relative to that of best pBLAST hit. No ORF identifier is given when ORF was too small to be recognized in initial annotation.

Whenever available, predictions were checked by comparison to homologous proteins with validated function and resolved crystal structure.

Alignment and phylogenetic analysis were performed with ClustalW 2.0 (Larkin et al., 2007) and MEGA 5.0 (Tamura et al., 2011).

\section{ACCESSION NUMBERS}

The Whole Genome Shotgun projects of Bacillus azotoformans LMG $9581^{\mathrm{T}}$ and Bacillus bataviensis LMG $21833^{\mathrm{T}}$ have been deposited at DDBJ/EMBL/GenBank under the accession numbers AJLR00000000 and AJLS00000000, respectively. The versions described in this paper are the first versions, AJLR01000000 and AJLS01000000.

\section{RESULTS AND DISCUSSION}

Bacillus azotoformans was originally isolated from garden soil and the organism has been known for decades to be a vigorous denitrifier (Pichinoty et al., 1983). Several biochemical studies investigating the enzymes involved in denitrification were conducted but no genomic data was available to aid interpretation of observations. Therefore, the genome of the type strain of the species was sequenced and the genes associated with dissimilatory nitrate reduction were analyzed. Unexpectedly, the genome contained the genes encoding both the complete denitrification pathway and nitrite ammonification (Table 2). No other organism is known to possess both pathways and also no experimental data has been reported that suggested their concurrence in one organism. This, however, may not be exceptional. Next to Bacillus azotoformans LMG $9581^{\mathrm{T}}$ we sequenced the genome of the type strain of B. bataviensis LMG $21833^{\mathrm{T}}$, originally isolated from soil (Heyrman et al., 2004). This strain was arbitrarily chosen, but it also contained the gene inventory for both processes (Table 3). Hereafter, we will discuss denitrification and ammonification in B. azotoformans step by step, after which both processes will be described for 
Table 3 | Overview of gene inventory involved in nitrogen assimilation, denitrification and ammonification of B. bataviensis LMG 21833 ${ }^{\top}$.

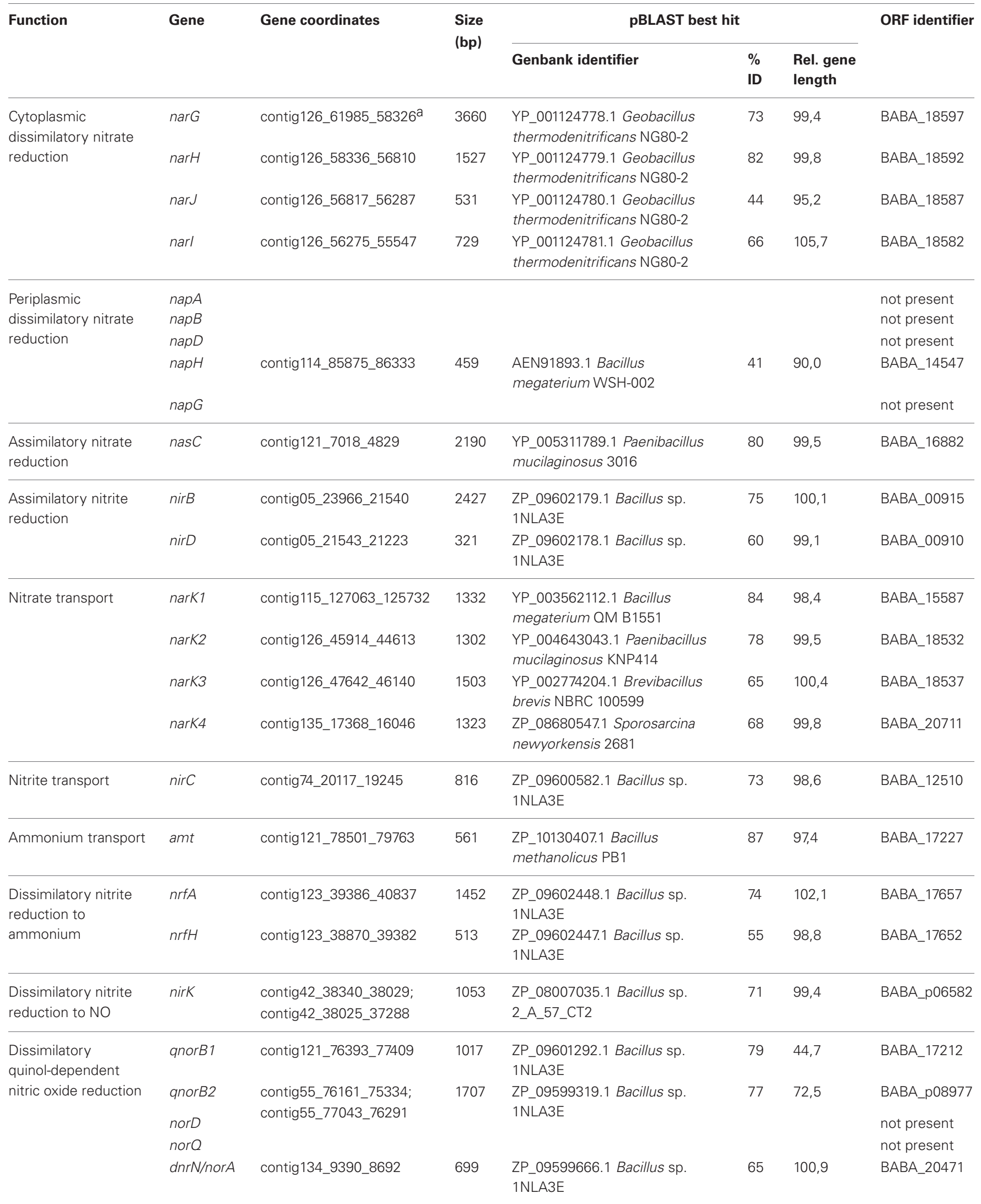


Table 3 | Continued.



Genes are ordered according to their location in the operon when applicable. Gene size is given in absolute numbers as well as relative to that of best pBLAST hit. No ORF identifier is given when ORF was too small to be recognized in initial annotation.

${ }^{a}$ The startcodon of BABA_18597 as deposited at DDBJ/EMBL/GenBank, contains a false start codon with an extra 30-bp sequence at the $5^{\prime}$ terminus.

B. bataviensis with an emphasis on the differences between both species.

\section{NITRATE REDUCTION}

The reduction of nitrate to nitrite in Bacteria is catalyzed by three different types of enzymes, that all bind a molybdenum bis molybdopterin guanine dinucleotide (Mo-bis-MGD) cofactor at the catalytic subunit together with a $4 \mathrm{Fe}-4 \mathrm{~S}$ cluster for electron transfer (Rothery et al., 2008). Two of these nitrate reductases (NARs) are involved in respiration, the cytoplasmic Nar, and the periplasmic Nap. The third one, Nas, acts in nitrogen assimilation and is localized in the cytoplasm. In the genome of B. azotoformans a gene coding for Nas is absent, but the organism contains the inventory for two functional Nar systems as well as one Nap protein complex (Figure 1). As yet, the presence of a periplasmic NAR has not been reported for a Gram-positive bacterium.

The Nar enzyme is composed of three subunits (NarGHI). In the genome, the genes coding for the three subunits are usually linked with the narJ gene encoding a maturation protein. NarGHI is well characterized by the resolution of the atomic structure of the enzyme from E. coli (Bertero et al., 2003, 2005). In the complex, NarG is the catalytic subunit housing the Mobis-MGD cofactor and a 4Fe-4S cluster. In Proteobacteria, NarG and $\mathrm{NarH}$ are localized in the cytoplasm, despite the presence in the former of a TAT signal for protein export, but the TAT sequence is non-functional (Ize et al., 2009). NarH binds three $4 \mathrm{Fe}-4 \mathrm{~S}$ clusters and one $3 \mathrm{Fe}-4 \mathrm{~S}$ cluster in tandem and mediates electron transfer between NarG and NarI. NarI is a membrane protein with five transmembrane helices (TMHs) that sandwich two cytochrome $b$ molecules, one near the cytoplasmic and the other one near the periplasmic face. In addition, NarI interacts with the electron donor for nitrate reduction, menaquinol, notably at the periplasmic side (Bertero et al., 2005). The complex is organized such that the uptake of two protons in the cytoplasm during nitrate reduction is associated with the release of two protons at the periplasm upon quinol oxidation, thus contributing to the building of proton-motive force ( $p m f$ ) by a redox loop mechanism (Rothery et al., 2008; Simon et al., 2008).

As mentioned, the genome of $B$. azotoformans codes for two different Nar systems (NarG1H1J1I1, BAZO_08891-08876; NarG2H2J2I2, BAZO_10677-10662) (Figure 1A). In both NarGs (with $74.9 \%$ aa sequence identity), all structurally relevant amino acids are fully conserved with respect to those in E. coli NarG (data not shown). Similarly, all structurally and functionally relevant amino acids are conserved in both $\mathrm{NarH}$ and NarI copies with respect to those of the E. coli enzyme. 


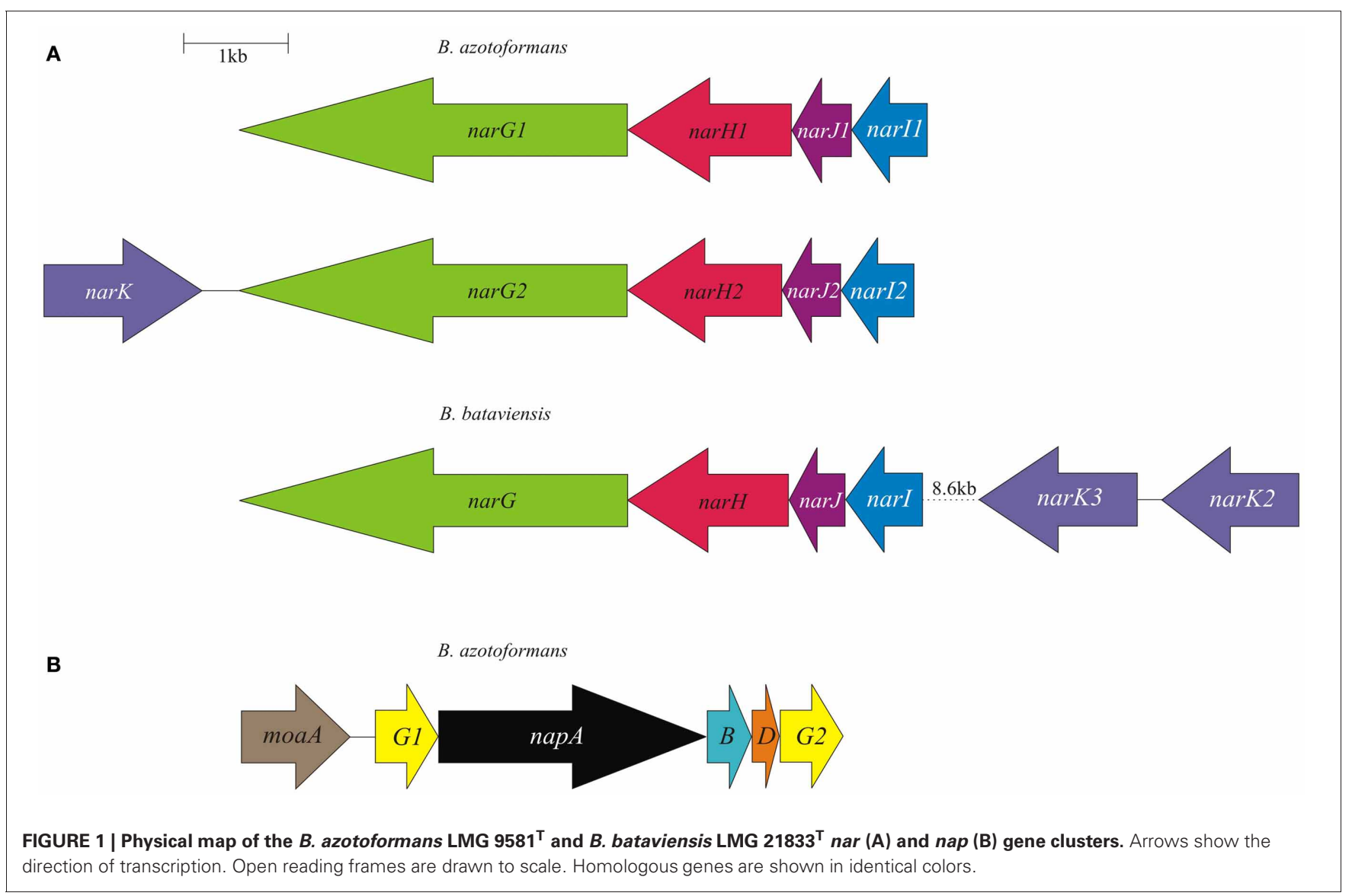

These observations indicate that the two B. azotoformans Nars are functional. NarG1 and NarG2 are devoid of a TAT signal sequence, indicative of their cytoplasmic localization. In agreement herewith, the narG2H2J2I2 gene cluster is linked to a gene coding for a protein (BAZO_10682) of the NarK family of nitrate transporters (Moir and Wood, 2001). More specifically, the pertinent protein is a member of the NarK2 subfamily of nitrate-nitrite antiporters. In other parts of the genome two genes (BAZO_00505, nirC1; BAZO_11644, nirC2) are found coding for members of the NirC/FocA Major Facilitator Superfamily (MFS). Proteins belonging to this superfamily facilitate the translocation across the cytoplasmic membrane of nitrite (NirC), formate (FocA), or even both (Moir and Wood, 2001; Falke et al., 2010). BAZO_11644 shows 97\% sequence identity to $f d h C$ gene product of Lactococcus lactis subsp. cremoris (YP_001032837). FdhC is a formate transporter associated with the formate dehydrogenase, which highly suggests a same function for BAZO_11644. A BlastP search indicates BAZO_00505 to be most closely related to putative formate/nitrite transporters from other Bacillus species including B. subtilis (NP_390598, $61 \%$ aa identity). As compared to FocA and NirC proteins of which the function has been established, sequence similarity of BAZO_00505 is higher with respect to the NirC members, which might imply that this B. azotoformans protein favors nitrite export.
The presence of a periplasmic NAR system comes as a surprise. Nature has invented several variations on the Nap theme (Simon and Klotz, 2012) and B. azotoformans adds one more. First of all, the nap gene cluster organization (napG1ABDG2moaA BAZO_15084-15059) is unusual with two copies of the napG gene (napG1, BAZO_15064; napG2, BAZO_15084) and the presence of a gene (moaA; BAZO_15069) coding for one of the enzymes involved in Mo-bis-MGD biosynthesis (Table 2; Figure 1B). The nap gene cluster is devoid of genes coding for $\mathrm{NapH}$, which is found in another part of the genome (BAZO_14359), whereas coding sequences for the cytoplasmic maturation factors NapF, a $4 \mathrm{Fe}-4 \mathrm{~S}$ protein, and NapL are completely absent. Furthermore, no gene accounting for quinoloxidizing membrane-bound $\mathrm{NapC}$ is found on the genome. These genes are also missing in Campylobacter jejuni, where $n r f H$ seems to replace napC (Pittman et al., 2007). Still, the available genes would suffice for an operational Nap system (González et al., 2006). In this system, NapA represents the catalytic subunit harboring a Mo-bis-MGD cofactor and a $4 \mathrm{Fe}-4 \mathrm{~S}$ cluster like in NarG. NapD is involved in the posttranslational assembly of NapA. NapA receives its electrons for nitrate reduction from the companion diheme $c$ protein NapB. NapAB are particularly well characterized by resolution of the crystal structures from at least four different species (Arnoux et al., 2003; Jepson et al., 2007; Kern and Simon, 2008; Najmudin et al., 2008; Coelho et al., 
2011). The comparison of the amino acid sequence of B. azotoformans NapA with those of known atomic structures reveals the conservation of all amino acids related with the binding of the molybdopterin cofactor and of the iron sulfur cluster. However, NapB contains some specific insertions and deletions with respect to NapB from Rhodobacter sphaeroides (Arnoux et al., 2003) and Cupriavidus necator (Coelho et al., 2011), possibly indicating somewhat different interactions with other subunits within the enzyme complex, but with conservation of the two heme $c$ binding sites (data not shown). B. azotoformans NapA contains a distinct TAT signal, whereas NapB has an N-terminal signal sequence, indicating that both proteins are exported to the periplasm, as expected. $\mathrm{NapH}$ and one or both NapG proteins most likely constitute a membrane-bound electron-transfer module, as has been established for other organisms (Richardson et al., 2001; Simon et al., 2003; Kern and Simon, 2008). NapH is a membrane-bound enzyme (with four TMHs) that specifically oxidizes menaquinol while NapG is a periplasmic adapter protein that is thought to deliver electrons from menaquinol oxidation (Kern and Simon, 2008). In agreement herewith, $\mathrm{NapH}$ from B. azotoformans is predicted to contain $4 \mathrm{TMHs}$, whereas two $\mathrm{Cx} 3 \mathrm{CP}$ motifs and the cysteines binding two $4 \mathrm{Fe}-4 \mathrm{~S}$ clusters in the periplasmic domain are fully conserved with respect to the NapH proteins from E. coli and P. denitrificans. Both NapG's are shorter than NapG from W. succinogenes (Kern and Simon, 2008), E. coli (YP_002403484.1), or Campylobacter upsaliensis (ZP_00370550.1) (198 for NapG1 and 189 for NapG2 vs 232-266 aa), lacking a C-terminal part. However, they still contain a $4 \mathrm{Fe}-4 \mathrm{~S}$ binding motif (Kern and Simon, 2008) suggesting functionality of both copies. As expected for the periplasmic localization of this iron-sulfur protein, NapG2 (BAZO_15084) has a clear TAT signal sequence, unlike NapG1 (BAZO_15064). Its absence would localize NapG1 in the cytoplasm. It is conceivable that the protein substitutes at this side for NapF found in other organisms. By the presence of the NapAB and NapGH modules, possibly assembled as one membrane-bound complex, B. azotoformans has the disposal of a second quinol-dependent NAR system. Presently, it is not understood why B. azotoformans as well as many other microorganisms harbor two dissimilatory reductases. By its topology and architecture, Nap is not expected to contribute to the pmf. It has been suggested that a main function of Nap would be nitrate-dependent regeneration of quinone from quinol that is produced in concert with the oxidation of the (organic) substrates (Richardson, 2000). Alternatively, the Nap module and the dissimilatory nitrite reductase (NrfHA) discussed next, may provide $B$. azotoformans with a high-affinity system for $\mathrm{N}$ assimilation under low nitrate conditions (Pittman et al., 2007; Kim et al., 2012).

\section{NITRITE REDUCTION}

In general, the one-electron reduction of nitrite to $\mathrm{NO}$ is catalyzed by two genetically and biochemically distinct nitrite reductases, the cytochrome $c d_{1}$ protein (NirS) and copper-containing NirK. B. azotoformans contains the latter representative (Table 2). DNRA bacteria possess NrfA as their key enzyme. Assisted by its redox partner $\mathrm{NrfH}$, NrfA catalyzes the six-electron reduction of nitrite to ammonium (Simon, 2002; Einsle, 2011;
Simon and Klotz, 2012). NrfHA can also be involved in stress response to nitric oxide, hydroxylamine, and hydrogen peroxide (Kern et al., 2011). B. azotoformans contains both NrfA and NrfH. In a similar fashion, the NirB and NirD proteins catalyze the $\mathrm{NAD}(\mathrm{P}) \mathrm{H}$-dependent reduction of nitrite to ammonium for nitrogen assimilation (Luque-Almagro et al., 2011), but homologs of these cannot be detected in the genome of B. azotoformans.

NirK is encoded by BAZO_03565 and the protein shows a high degree of identity with known NirKs of which crystal structures are available (Ellis et al., 2001; Tocheva et al., 2004; Jacobson et al., 2005; Fukuda et al., 2011). Among the structurally well characterized proteins, sequence identity $(80 \%)$ is highest with NirK (GK0767; YP_146620) from Gram-positive Geobacillus kaustophilus (Fukuda et al., 2011). BAZO_03565 shares three characteristic loop regions, with deletions in the "linker loop" and "tower loop," as well as an "extra loop." These features are typical for the NirK2 family (Boulanger and Murphy, 2002). The tower loop was suggested to "facilitate a more intimate interaction with the lipid membrane" (Boulanger and Murphy, 2002). BAZO_03565 is preceded by a Sec signal for protein export, indicative of a periplasmic localization of the processed protein. Such localization holds for all NirKs known to date. Quite interestingly, the LipoP program predicts the B. azotoformans protein to be a lipoprotein. Such covalent binding confirms results by Suharti and de Vries (2005), who found that nitrite reductase activity of B. azotoformans NCCB 10003 was exclusively associated with the membrane fraction. We may note that NirK from randomly chosen Gram-positive bacteria [Geobacillus thermodenitrificans NG80-2 (GTNG_0650), Geobacillus kaustophilus HTA-426 (GK0767), and Geobacillus thermoglucosidasius C56YS93 (Geoth_3084)] are also identified as putative lipoproteins. Suharti and de Vries (2005) proposed NirK from B. azotoformans to be a dual-function enzyme: it could use both menaquinol and reduced cytochrome $c$ as electron donors. However, it remained unclear whether menaquinol acted in a direct way, via a menaquinol oxidizing enzyme, or indirectly via the action of menaquinol: cytochrome $c$ oxidase ( $b_{6} f$, complex III; see below). Unfortunately, BAZO_03565 takes an isolated position within the genome and the gene context does not give a clue about its redox partners. This is in contrast with observations in the genomes of closely related denitrifiers Geobacillus thermodenitrificans (Feng et al., 2007) and G. kaustophilus, in which the nirK is imbedded in a gene cluster with genes encoding NAR and associated proteins, NOR genes, a nitrate transporter, and several regulatory genes.

Ammonium-forming nitrite-reducing NrfHA are encoded by BAZO_03250-03255 (Table 2). The nrfHA operon organization is similar to that described for several bacteria capable of DNRA such as Campylobacter jejuni, Desulfovibrio vulgaris, Geobacter sulfurreducens (Simon, 2002), and Desulfitobacterium hafniense DCB-2 (Kim et al., 2012). NrfA is a periplasmic pentaheme $c$ protein in which four cytochromes $c$ are involved in electron transfer while the fifth one has a catalytic function. Their presence in the amino acid sequence is characterized by $\mathrm{CXXCH}$ (electron transfer) and CXXCK (catalysis) motifs. BAZO_03255, indeed, shows these motifs and it displays 
also all other sequence features of NrfA proteins of which crystal structures are available (Bamford et al., 2002; Cunha et al., 2003; Rodrigues et al., 2006a) (Figure A1). Consistent with the localization of all known NrfA's, BAZO_03255 contains an N-terminal signal sequence for protein export. Known NrfA's are soluble proteins, but the LipoP program predicts BAZO_03255 to be a lipoprotein. As far as could be checked, the lipoprotein nature might also hold for NrfA's from other Firmicutes, namely Bacillus selenitireducens MLS10 (Bsel_1305) and Desulfitobacterium hafniense DCB-2 (Dhaf_4234). NrfH is a membrane-bound tetraheme cytochrome $c$ belonging to the NapC/NirT family of menaquinol oxidases (Simon et al., 2000). The comparison with $\mathrm{NrfH}$ from the Deltaproteobacterium Desulfovibrio vulgaris, of which the structure has been resolved (Rodrigues et al., 2006b, 2008), establishes the conservation in BAZO_03250 of all relevant amino acids implemented with structuring the $\mathrm{N}$-terminal $\mathrm{TMH}$, quinol binding, and ligation of the four hemes $c$. Taken together, our observations indicate that both NrfA and NrfH are functional proteins in B. azotoformans. As a membrane-bound complex, NrfAH would facilitate in $B$. azotoformans menaquinol oxidation coupled with the reduction of nitrite making ammonium. One may note that both proteins are rich in heme $c$ molecules. In this respect it is interesting that $n r f A H$ is linked to a gene cluster (ccmEFHABC; BAZO_03265-BAZO_03300) encoding six out of eight proteins of the System I cytochrome $c$ biogenesis machinery (Kranz et al., 2009).

It now appears that $B$. azotoformans has the disposal of two parallel pathways for nitrite reduction enabling a life style as a denitrifier and as a DNRA bacterium. It has been argued that denitrification is more favorable under carbon limitation, whereas as nitrate/nitrite ammonification is more attractive under electron acceptor limitation (Tiedje et al., 1982; Tiedje, 1988). By the presence of the two, $B$. azotoformans may benefit from the best of two worlds. Still, the metabolism leaves us with one puzzle. One may note that the organism is devoid of the assimilatory nitrate and nitrite reductases. This would make B. azotoformans dependent on ammonium as the nitrogen source. Obviously, ammonium can be produced by the action of the Nar, Nap, and Nrf systems and even more so, since nrfA in E. coli is known to be expressed under low nitrate conditions, while NirB operates at high nitrate concentrations (Wang et al., 2000). So, B. azotoformans might have adapted to low nitrate/nitrite conditions. The problem, however, is that no gene is found in the genome of $B$. azotoformans coding for a known (AmtB-type) transporter to take periplasmically produced ammonium into the cell.

\section{NITRIC OXIDE REDUCTION TO NITROUS OXIDE}

The product of nitrite reductase NirK, NO, is a very reactive and toxic free radical compound and a range of known or predicted but still to be validated enzymes exists to convert it into $\mathrm{N}_{2} \mathrm{O}$ (Richardson, 2000; de Vries and Schröder, 2002; Tavares et al., 2006; Hemp and Gennis, 2008; Watmough et al., 2009; Kraft et al., 2011; Martínez-Espinosa et al., 2011; Stein, 2011). NORs fall into two different classes: (1) NorVW flavorubredoxin that is employed by many organisms for NO detoxification in response to nitrosative stress from the environment and (2) NORs belonging to the heme-copper oxidase (HCO) superfamily. The enzymes combine two $\mathrm{NO}$ molecules to make $\mathrm{N}_{2} \mathrm{O}$ by the input of two electrons. Presently, three types of NORs have been studied in some detail: (1) cNOR (or NorBC) that uses reduced cytochrome $c$ as the reductant, (2) quinol-dependent qNOR (qNorB), and (3) $\mathrm{qCu}_{\mathrm{A}} \mathrm{NOR}$ that takes both as electron donors. For $\mathrm{cNOR}$ and qNOR atomic structures are available (Hino et al., 2012; Matsumoto et al., 2012). Presently, only one $\mathrm{qCu}_{\mathrm{A}} \mathrm{NOR}$ has been purified, notably from Bacillus azotoformans NCCB 10003 that is closely related to the strain (LMG 9581 ${ }^{\mathrm{T}}$ ) discussed here (Suharti et al., 2001, 2004; Lu et al., 2004). The enzyme was reported to be composed of two subunits, a small $\mathrm{Cu}_{\mathrm{A}}$-type subunit and a large one with two heme $b$ molecules. Although quite well characterized, the encoding genes remained elusive.

Besides NORs, the HCO superfamily comprises a broad variety of terminal oxidases (Hemp and Gennis, 2008; Sousa et al., 2012). The common property is a membrane-bound catalytic subunit with 12-14 TMHs that bind a heme $b$ (or $a$ ) for electron transfer and a second heme $\left(b_{3}, a_{3}\right.$, or $\left.o_{3}\right)$ constituting the catalytic center together with an iron $\left(\mathrm{Fe}_{\mathrm{B}}\right.$ in NOR) or a copper ion $\left(\mathrm{Cu}_{\mathrm{B}}\right.$ in oxidases). Both $\mathrm{Fe}_{\mathrm{B}}$ and $\mathrm{Cu}_{\mathrm{B}}$ are ligated by three conserved histidines. Next, two histidines coordinate the electron-transferring heme, whereas one more histidine serves as the proximal ligand to the catalytic heme. This histidine sextet is a signature for HCOs. Oxidases are distinguished by the presence of a tyrosine near the catalytic side that makes a covalent bond with one of the histidines binding $\mathrm{Cu}_{\mathrm{B}}$. In NORs the pertinent tyrosine is replaced by a glutamate, glutamine, aspartate, or asparagine (Hemp and Gennis, 2008). Moreover, in certain NOR types one of the $\mathrm{Cu}_{\mathrm{B}}$ - or $\mathrm{Fe}_{\mathrm{B}}$-ligating histidines is substituted by an aspartate (Hemp and Gennis, 2008; Sievert et al., 2008). Besides the catalytic subunit, heme copper oxidases may contain one or more additional subunits for electron transfer as well as membranespanning polypeptides for structural integrity. Electron transfer subunits have heme $c$ or copper $\left(\mathrm{Cu}_{\mathrm{A}}\right)$-containing cupredoxins as redox components. In addition, heme copper oxidases are distinguished on the basis of their use of the electron donors for $\mathrm{O}_{2}$ or NO reduction, which can be either reduced cyt $c$ or quinol.

While cNORs are absent in the genome of B. azotoformans, we could identify two genes coding for qNORs, BAZO_00190, and BAZO_08916. The preference for quinol-dependent NOR seems to be a common property of Gram-positive microorganisms. Although BAZO_00190 and BAZO_08916 share only 38\% sequence identity, the comparison of their amino acid sequences with those of which the functions have been established, including qNOR from Geobacillus stearothermophilus having a known crystal structure (Matsumoto et al., 2012) (Figure A2), suggests functionality of both B. azotoformans proteins. Briefly, BAZO_00190 and BAZO_08916 are composed of one subunit in which 13 TMHs surround the catalytic module. A 14th (N-terminal) TMH precedes a soluble domain facing the periplasm with a heme $c$ fold, but heme $c$ itself is absent. In both proteins amino acids are conserved binding both heme $b$ molecules, non-heme iron, a specific calcium atom, the quinol substrate as well as the amino acids lining a proposed water/proton channel down from cytoplasm to the catalytic side, hydrophobic amino acids along two other 
putative water channels, and aromatic amino acids that stabilize that heme $c$ fold of the soluble domain (Figure A2).

cNOR (NorBC) activity depends on ancillary proteins (NorDEFQ) that tend to be encoded on the same operon as the structural proteins (Zumft, 2005b), but qNOR can do without these. Nevertheless, genes norDQ (BAZO_01537; BAZO_01542) are present in the genome, although not directly linked to BAZO_00190 and BAZO_08916. This is also the case in genomes of other Gram-positives harboring the qnorB gene, including G. thermodenitrificans NG80-2, G. kaustophilus HTA-426, Anoxybacillus flavithermus WK1, Bacillus licheniformis ATCC 14580, Oceanobacillus iheyensis HTE831, making it a common observation among Gram-positives. However, it is difficult to speculate on their necessity for qNOR functionality in these organisms, as the precise functions of NorD and NorQ remain to be established. In addition, the genome of $B$. azotoformans contains the norA gene (BAZO_04395), also termed $d n r A$ or $s c d A$ ), which codes for a putative iron-sulfur cluster repair protein in response to NO damage (Overton et al., 2008).

Besides the two qNORs, no less than four gene clusters are found in the genome of $B$. azotoformans encoding members of the HCO superfamily that share significant sequence homology with cytochrome $c$-dependent $b a_{3}$ oxidase (CbaAB) from Thermus thermophilus (Figures A3, A4). This is a terminal oxidase that is structurally and functionally quite well investigated [see amongst others: Soulimane et al. (2000); Fee et al. (2008); Smirnova et al. (2008); Liu et al. (2012); von Ballmoos et al. (2012)]. ba $a_{3}$-type oxidase receives its electrons for $\mathrm{O}_{2}$ reduction from cyt $c$. The electrons are transferred via $\mathrm{Cu}_{\mathrm{A}}$ in subunit II $(\mathrm{CbaB})$, and cyt $b$ in subunit I (CbaA) to the $a_{3}-\mathrm{Cu}_{\mathrm{A}}$ catalytic center in this subunit. In agreement herewith, all amino acids that had been structurally assigned to $\mathrm{Cu}_{\mathrm{A}}$ binding and to electron transfer were conserved in the B. azotoformans subunits II (Figure A4). Importantly, the N-terminal sequence of BAZO_06394 (MHKSEKIWLTLSFGMIMGFM) is identical to the one of subunit II of $\mathrm{qCu}_{\mathrm{A}} \mathrm{NOR}$ published by Suharti et al. (2001). These authors (Suharti et al., 2004) also presented the N-terminal sequence of the large subunit (MTKKNTQEVVKEGREGIGTFIGVGIVGAV), but this was not found in the corresponding subunit I (BAZO_06399). Rather, the almost identical sequenceMATTKNTQEVVKEGREGIGTFIGVGIVGAV—was retrieved in the adjacent gene (contig42_104893_105033) (Figure 2A). This gene encodes a small (46 amino acids) membrane-bound peptide. Hence, it is very well conceivable that this peptide formed part of the enzyme preparation purified by Suharti et al. (2001, 2004). The comparison of the amino acid sequence of subunit I (BAZO_06399) with that of $b a_{3}$ from T. thermophilus revealed that the tyrosine (Y223, T. thermophilus numbering in Figure A3) covalently binding a $\mathrm{Cu}_{\mathrm{B}}$-associated histidine (H219) was substituted by an asparagine in the B. azotoformans protein, in agreement with predictions made by Hemp and Gennis (2008) for NOR functionality (Figure A3). These findings identify BAZO_06394-BAZO_06399 as the dual-function quinol and cyt
A
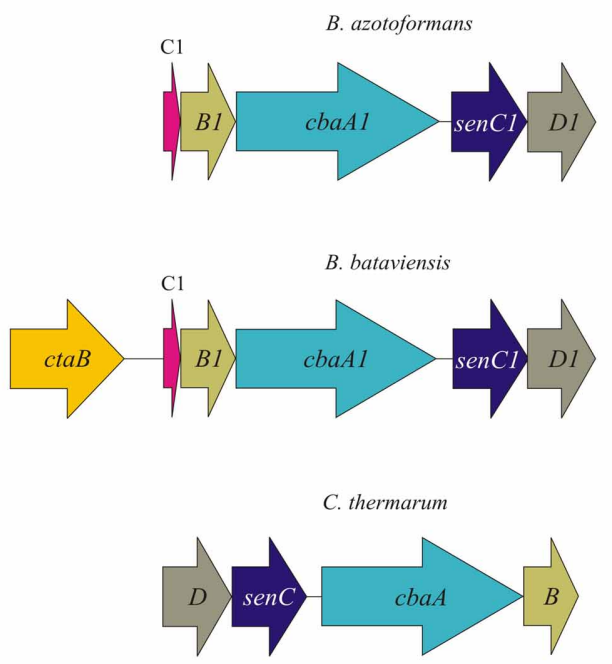

$1 \mathrm{~kb} \mid$
B
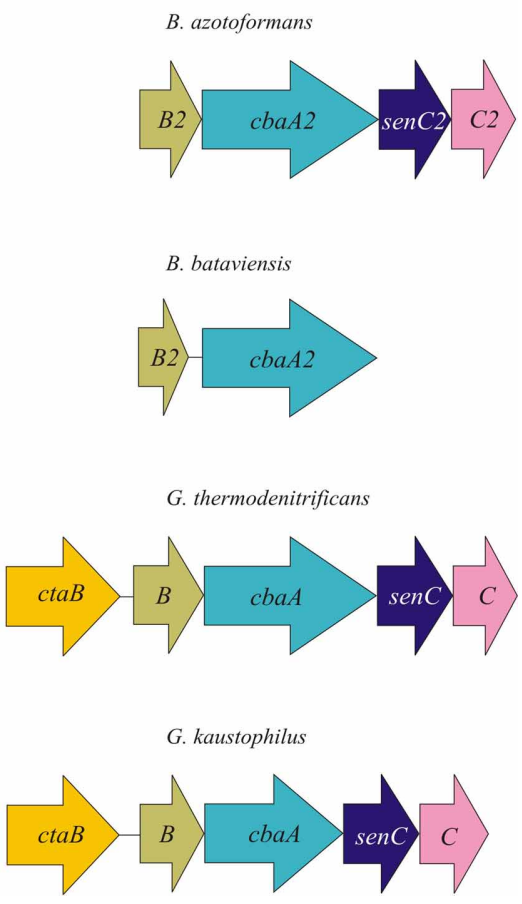

NG80-2, and G. kaustophilus HTA426. Arrows show the direction of transcription. Open reading frames are drawn to scale. Homologous genes

are shown in identical colors.
FIGURE 2 | Physical map of $q \mathrm{qu}_{A}$ NOR type I (A) and $q \mathrm{Cu}_{A}$ NOR type II (B) gene cluster in $B$. azotoformans LMG $9581^{\top}$, B. bataviensis LMG $21833^{\top}$, Caldalkalibacillus thermarum TA2.A1, Geobacillus thermodenitrificans 
c-dependent $\mathrm{qCu}_{\mathrm{A}} \mathrm{NOR}$ described by Suharti et al. $(2001,2004)$. We may note that the genes coding for these three subunits are linked to two other ones, one (BAZO_06404) coding for a SenC/SCO1-type membrane-bound protein that has been implemented with the insertion of copper $\left(\mathrm{Cu}_{\mathrm{A}}\right)$ into subunit I, and BAZO_06409 that is predicted to comprise six TMHs (Figure 2A). In protein databases, homologs of the latter are found being annotated as cyt $c$ oxidase-associated membrane proteins. Furthermore, the presence of BAZO_06394-06399 $\mathrm{qCu}_{\mathrm{A}} \mathrm{NOR}$ is not restricted to $B$. azotoformans and $B$. bataviensis (see below), but close homologs sharing the same sequential features and the same cluster organization are found in various other Gram-positive bacteria, including Caldalkalibacillus thermarum TA2, but also in Nitrosomonas eutropha and other nitrifiers (Figure 2A and data not shown). In N. eutropha the particular NOR was designated sNOR (Stein et al., 2007). Transcriptome analysis suggested sNOR as a suitable candidate for aerobic NO reduction, next to NorBC (Cho et al., 2006).

$B$. azotoformans likely contains one more novel type of $\mathrm{qCu}_{\mathrm{A}} \mathrm{NOR}$ (type II) of which the subunits I and II are encoded by BAZO_04705 and BAZO_04710, respectively (Figure 2B). Again, subunit II is of the $\mathrm{Cu}_{\mathrm{A}}$-type and in subunit I the cross-linking tyrosine is substituted by an asparagine (Figures A3, A4). At the C-terminal part, the large subunit I is substantially shorter than in the previous case and in T. thermophilus $b a_{3}$ oxidase, yet with the conservation of all general HCO characteristics. Being shorter, subunit I is predicted to be structured by $12 \mathrm{TMHs}$, instead of 13. In contrast, subunit II contains two N-terminal TMHs, one more than in BAZO_06394, and subunit II of T. thermophilus $b a_{3}$ oxidase. As above, BAZO_04705-04710 are linked to genes encoding a SenC/SCO1 paralog (BAZO_04700) and a polypeptide (BAZO_04695) with 4-5 predicted TMHs that might constitute a third subunit. Again, the presence of the BAZO_04695-4710 is not restricted to B. azotoformans. Close homologs, both at the sequence and cluster organization levels, are found in other Gram-positive bacteria, including G. thermodenitrificans NG80-2 (GTNT_1517-1520) and G. kaustophilus HTA-426 (GK1670-1673) (Figure 2B and data not shown). Quite remarkably, the gene clusters in both Geobacillus species are associated with ones coding for heme $o$ oxygenase (GTNG_1516, GK1690). This enzyme converts heme $o$ into heme $a$. This might imply that that the Geobacillus enzymes would contain heme $a$ instead of heme $b$, thereby inventing one more variation on the NOR theme.

The two remaining $b a_{3}$ oxidase-related $\mathrm{HCO}$ members (BAZO_09851-09846, BAZO_10757-10762) are highly related to one and another. Their large (BAZO_09851, BAZO_10757) and small subunits (BAZO_09846, BAZO_10762) are 83 and $90 \%$ identical, respectively. However lacking the first $31 \mathrm{~N}$ terminal amino acids, BAZO_10762 is markedly shorter than BAZO_09846 (128 vs 159 aa). Sequence analyses suggest these HCOs to be genuine $\left(\mathrm{O}_{2}\right.$-reducing) oxidases, having a tyrosine for histidine cross linking. At the sequence levels, the large (I) and small (II) subunits of both B. azotoformans proteins are 40 and $45 \%$ identical to the ones of $b a_{3}$ oxidase from $T$. thermophilus (Figures A3, A4). The differences in amino acid sequences might suggest that the large subunits could bind other hemes and/or differ in the nature of the proton channels. Indeed, sequence identities of BAZO_09851 and BAZO_10757 are significantly higher $(67 \%)$ with respect to the large subunit of $b_{3}$ cytochrome $c$ oxidase isolated from Geobacillus (previously Bacillus) stearothermophilus having heme $o_{3}$ at the catalytic side (Sakamoto et al., 1997; Nikaido et al., 1998). The latter protein catalyzes $\mathrm{O}_{2}$ reduction with reduced cyt $c_{551}$, a lipoprotein, as the specific reductant $\left(K_{\mathrm{m}}=0.15 \mu \mathrm{M}\right)$. The $b o_{3}$ cytochrome $c$ oxidase actively pumps protons across the cell membrane during the reaction. It is not known if quinol can substitute for cyt $c_{551}$ as electron donor. Also here, the genes coding for both B. azotoformans oxidases are linked to ones (BAZO_09841, BAZO_10767) encoding small membrane-bound polypeptides (46 amino acids) possibly serving as a third subunit. We may note that close homologs to BAZO_09851-09841 and BAZO_10757-10767 are present in G. thermodenitrificans NG80-2 (GTNT_1394-1396) and G. kaustophilus HTA-426 (GK1546-1548), as well as in many other Bacillus-related species.

For oxygen respiration, model organism Bacillus subtilis strain 168 has the disposal of four different oxidases, cyt $c_{551}$-dependent $\mathrm{Caa}_{3}$ oxidase, which is preferentially used at high oxygen concentrations, and three types that rely on quinol: $a a_{3}-600$ oxidase, bd oxidase, and a bb' oxidase (Lauraeus et al., 1991; Azarkina et al., 1999; Winstedt and von Wachenfeldt, 2000). Apart from the $b(a / o)_{3}$-type oxidase discussed before, which seems to be absent in B. subtilis, the genome of $B$. azotoformans has the inventory of two of these. Genes coding for $b d$ oxidase are not found in B. azotoformans, unlike many other Bacillus species including $B$. bataviensis discussed below. Four-subunit quinoldependent $a a_{3}-600$ oxidase encoded by the qoxBACD genes are represented by the gene products of BAZO_10131-10146 (subunit II, BAZO_10131; subunit I, BAZO_10136; subunit III, BAZO_10141; subunit IV, BAZO_10146). Amino acid sequences of the $B$. azotoformans gene products readily compare those of established functions. Cyt $c$-dependent $\mathrm{caa}_{3}$ oxidase is also composed of four subunits (CtaCDEF). The structural genes are usually clustered with genes coding for accessory proteins, including $\mathrm{CtaB}$ and CtaA that catalyze the subsequent conversion of heme $b$ into heme $o$ and heme $a$, and $\mathrm{CtaG}$, a cytochrome $c$ oxidase assembly factor. The gene cluster organization (ctaABCDEFG) is conserved in B. azotoformans (BAZO_04065-BAZO_04035). Furthermore, the individual gene products are well conserved with respect to the ones of which the function has been established. These observations support functionality of both quinoldependent $a a_{3}-600$ (QoxBACD) and of cyt $c$-dependent $c a a_{3}$ oxidase (CtaCDEF) in B. azotoformans.

By exploiting variations on the $\mathrm{HCO}$ theme, B. azotoformans harbors a repertoire of four different NO reductases and four different oxidases that utilize reduced cyt $c$ and/or quinol as reductants. Obviously, this repertoire and the branching in electron transfer may lend the organism the metabolic versatility to cope with large changes in respiratory conditions in the environment.

\section{NITROUS OXIDE REDUCTION}

The last step in the denitrification pathway to dinitrogen gas is the two-electron reduction of $\mathrm{N}_{2} \mathrm{O}$ to produce, with the input 
of two protons, $\mathrm{N}_{2}$ and water. While the previous steps can be catalyzed by different types of enzymes, only one exists for $\mathrm{N}_{2} \mathrm{O}$ reduction, nitrous oxide reductase (NOS, $\mathrm{N}_{2} \mathrm{OR}$, NosZ) [see for reviews Zumft (1997, 2005a,b); Zumft and Kroneck (2007)]. NOS is a homodimeric protein with two multinuclear copper centers. In all organisms investigated thus far, it is located in the periplasm and in Gram-negative species it is a soluble protein. For its assembly, NOS depends on a number of accessory proteins (NosADLYF). Assembly is thought to take place in the cytoplasm after which NOS is exported using the TAT translocon. In Gram-negative bacteria, the TAT signal sequence is unusual long counting approximately fifty amino acids.

The genome of $B$. azotoformans encodes no less than five nos gene clusters, with three clusters including a nos $Z$ gene, and one orphan nosF (Table 2, Figure 3A). Gene arrangements differ in every cluster (Figure 3A), but they are most similar to the atypical nos gene cluster (nosCZ-ORF-nosDYFORF) found in the three other Gram-positives available in the databases with nos genes: Geobacillus thermodenitrificans NG802 (Figure 3B), Desulfitobacterium hafniense T51 (Liu et al., 2008), and Desulfotomaculum ruminis DSM 2154. Each nos $Z$ gene is consistently preceded by nos $C$, coding for a cytochrome $c$, which is predicted (LipoP) to be a lipoprotein with the heme $c$ part facing the periplasm. Nos $Z$ is followed by a conserved hypothetical open reading frame encoding a membrane protein with four predicted
TMHs. Interestingly, the latter is also the case in W. succinogenes (Ws0918) (Simon et al., 2004). In W. succinogenes, the two copies of $n o s C$ are located downstream of nos $Z$ and are flanked by nos $G$ and nosH genes, which are absent in B. azotoformans. NosGH represent a membrane-bound quinone-oxidizing electron transfer module, resembling NapGH in the periplasmic NAR (Nap) system described above. B. azotoformans also lacks a nos $A$ gene that codes for a periplasmic accessory protein involved in $\mathrm{Cu}$ binding. However, we note the presence of one of the four senC/SCO1 paralogs upstream of nosC3. As mentioned before, SenC has been implemented with the insertion of copper $\left(\mathrm{Cu}_{\mathrm{A}}\right)$; genes coding for the other three paralogs are associated with the alternative NORs. NosL, which is present in three copies in the nos gene clusters (Figure 3A), is a lipoprotein that stoichiometrically binds $\mathrm{Cu}$. This property suggests NosL to be a copper chaperone for metalcenter assembly (Zumft, 2005a). NosDYF represent a Cu-ABC transport system with a periplasmic $\mathrm{Cu}$-binding protein (NosD), a membrane-bound permease (NosY), and a cytoplasmic ATPase (NosF) that provides the driving force for $\mathrm{Cu}$ translocation (Zumft, 2005a). As can be seen from Figure 3A, nosDYF come in different arrangements in the genome of $B$. azotoformans, either with or not associated with NosZ. Moreover, sequence analysis reveals marked differences among the individual gene products. All five nos $D$ gene products have a putative transmembrane helix at the C-terminus, but only three of these have a predicted

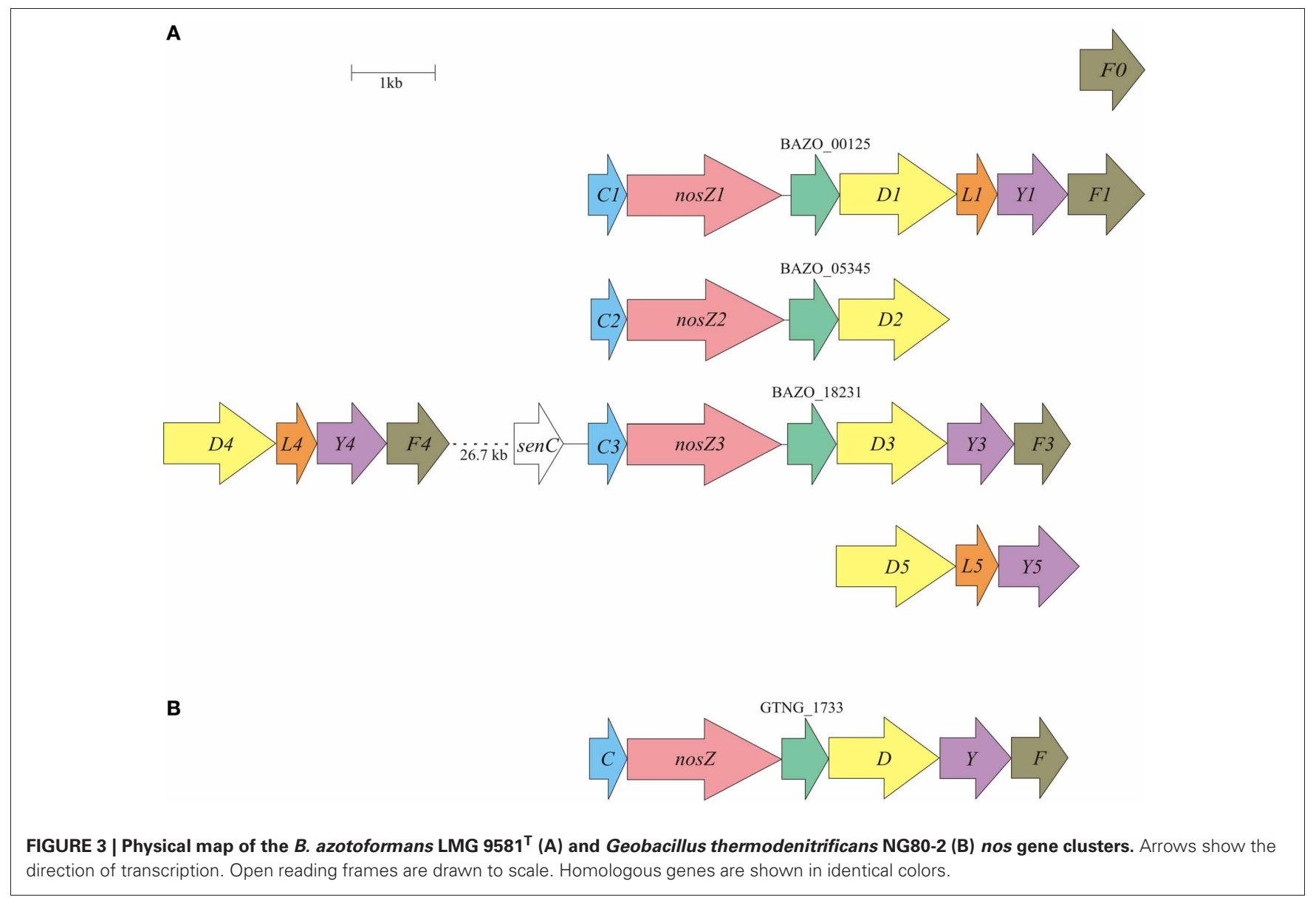


Sec-signal (NosD1, BAZO_00130; NosD4, BAZO_18066; NosD5, BAZO_14249), as expected for periplasmic proteins. NosY3 contains a seventh TMH, one more than usual, while significant insertions without any known domain are found in NosY4 (39 $\mathrm{AA}$ at the $\mathrm{N}$-terminus) and NosF1 (49 AA at the C-terminus). Regardless of these differences, B. azotoformans has the disposal of a multicopy factory that could supply NosZ, and possibly also other copper proteins like NirK, with the high demand on copper (Richardson et al., 2009).

The deduced primary structure of the three B. azotoformans NosZ proteins (between 76.5 and $83.1 \%$ sequence identity) show all conserved ligands of $\mathrm{Cu}_{\mathrm{A}}$ and $\mathrm{Cu}_{Z}$ centers that have been identified in the crystal structures (Figure A5) (Brown et al., 2000; Paraskevopoulos et al., 2006). Nevertheless, the NosZ sequences contain insertions and deletions that are shared with nitrous oxide reductases from other Gram-positive species, likely placing these in a distinct family. The differences could be related with domain-specific interactions in Gram-positives and Gramnegatives with other components of the NosZ system. Another feature is that the N-terminal sequence in Gram-positive NosZ's is shorter (Figure A5). Moreover, SignalP and TatP prediction programs are somewhat ambiguous regarding the presence of N-terminal leader and TAT signal sequences. For instance, whereas NosZ1 from B. azotoformans is predicted to have a TAT leader, yet lacking an $\mathrm{N}$-terminal cleavage side, the opposite holds for NosZ2 and NosZ3. These differences might point to, even protein-specific, differences in assembly, and transport. It is conceivable that transport proceeds not only by the TAT—-but also by the Sec translocon. Indeed, it has been described for W. succinogenes that transport of non-folded NosZ and subsequent $\mathrm{Cu}$ insertion results in a fully functional protein (Heikkilä et al., 2001).

NosZ from Gram-negative bacteria is, as mentioned, a soluble protein in the periplasm where it receives its electrons for $\mathrm{N}_{2} \mathrm{O}$ reduction from reduced cytochrome $c$. In Gram-positive microorganisms, including B. azotoformans strain NCCB 10003, nitrous oxide reductase activity appears to be associated with the membrane fraction only [(Suharti and de Vries, 2005), and references herein]. Considering that the B. azotoformans NosZ gene products do not possess any TMH other than an N-terminal Sec-or TAT-signal, the conserved ORF encoding the polypeptide with four TMHs might provide a platform for membrane association. In addition, $B$. azotoformans nitrous oxide reductase(s) employ both cyt $c$ and menaquinol as electron donors (Suharti and de Vries, 2005). Clearly, the particular lipoprotein cytochromes $c$ that are encoded by the nos $C$ genes might assist in cyt $c$-dependent electron transfer, but the role of menaquinol is more puzzling. Menaquinol could act directly or indirectly, viz. via menaquinol: cytochrome $c$ oxidoreductase $\left(b c_{1} / b_{6} f\right.$ complex; see hereafter). A more direct role presumes the presence of a membrane-bound quinol oxidase in contact with NosZ. Here, the conserved membrane protein would come to mind. Alternatively, NapGH might serve such function. Experimental research has to decide between these or other alternatives.

\section{$b c_{1} / b_{6} f$ COMPLEX OF $B$. azotoformans}

In nitrate/nitrite-respiring Gram-negative bacteria, (mena) quinol: cytochrome $c$ oxidoreductase $\left(b c_{1}\right.$ complex $)$ plays a central role in the energy metabolism. By the complex, quinol that is produced concomitant to the oxidation of (organic) substrates is re-oxidized with cyt $c$ as electron acceptor. Taking advantage of the proton-motive $\mathrm{Q}$ cycle, quinol:cyt $c$ oxidoreduction is associated with the pumping of protons $\left(4 \mathrm{H}^{+} / 2 \mathrm{e}^{-}\right)$ across the cell membrane. Reduced cyt $c$ serves as the reductant of the nitrate-reducing steps that, in case of a localization in the periplasm, do not contribute to pmf generation themselves. The work by the group of de Vries (Suharti et al., 2004; Suharti and de Vries, 2005) demonstrates that B. azotoformans opts for branched electron transfer, using both quinols and reduced cyt $c$ for denitrification (see also above). While the cyt $c$-dependent pathway is energetically more favorable, a direct coupling of the denitrification steps with quinol oxidation could be kinetically more attractive (Suharti et al., 2004; Suharti and de Vries, 2005). The former pathway calls for the presence of a $b c_{1} / b_{6} f$ complex in B. azotoformans, as well as suitable cytochromes $c$ for electron transfer.

In its simple, canonical form the $b c_{1}$ complex comprises three subunits: a Rieske-type $2 \mathrm{Fe}-2 \mathrm{~S}$ protein and a membrane protein that binds one heme $b$ and one quinone at the cytoplasmic face and another heme $b$ and a quinone near the periplasm. The third component is cyt $c$. In Bacillus subtilis, the organization of the complex is different, resembling $b_{6} f$ complexes of Cyanobacteria and chloroplasts (Yu et al., 1995; Yu and Le Brun, 1998). The Rieske iron sulfur protein (QcrA) is of a general type, but the cytochrome $b$ subunit is split into two parts (QcrA and QcrB). QcrB is homologous to the N-terminal part and QcrC is to the C-terminal part of common cytochrome $b$ and of subunit IV of the $b_{6} f$ complex. At its N-terminus, QcrC is fused to a $c$-type cytochrome localized in the periplasm. The particular organization and the related amino acid sequences are conserved in QcrA (BAZO_09251), QcrB (BAZO_09246), and QcrC (BAZO_09241) from B. azotoformans (data not shown). We note the presence in the qcrABC gene cluster of a set of flanking genes coding for membrane-bound proteins (BAZO_09231; BAZO_09236; BAZO_09261) and for proteins with tetratrico peptide repeats (TPR) (BAZO_09256; BAZO_09266). Their presence is conserved in many Bacillus species, including B. bataviensis. This observation might suggest $b_{6} f$ of these organisms to be more "complex."

For electron transfer, B. subtilis has the disposal of only two small membrane-bound $c$-type cytochromes: CccB, a cyt $c_{551}$ lipoprotein, and CccA, a cyt $c_{550}$ that is anchored to the membrane by a single C-terminal TMH (Bengtsson et al., 1999). De Vries and coworkers (Suharti et al., 2004; Suharti and de Vries, 2005) were able to isolate and characterize three different types of monoheme cytochrome $c$-type lipoproteins from B. azotoformans, namely cyt $c_{550}$, cyt $c_{551}$, and cyt $c_{552}$; their encoding genes were not identified. All three could be reduced in concert with menaquinol oxidation by the $b_{6} f$ complex. Cyt $c_{551}$ functioned as the specific electron donor to $\mathrm{qCu}_{\mathrm{A}} \mathrm{NOR}$, but it was inactive in nitrite and in nitrous oxide reduction. In addition, pseudoazurin or other cupredoxins, the principal electron donors for coppercontaining NirK, appeared to be absent (Suharti and de Vries, 2005). Now looking at the genome of B. azotoformans, we note the presence of four genes coding for monoheme cyt $c$-type 
lipoproteins, three of which being linked to the nos $Z$ genes (see above). This would leave the gene product of the fourth candidate (BAZO_07449)—indeed annotated as cyt $c_{551}$ —as the electron carrier for $\mathrm{qCu}_{\mathrm{A}} \mathrm{NOR}$. Furthermore, diheme cyt $c_{5}$ is specifically required for NirK activity in Neisseria meningitides (Deeudom et al., 2008). The genome of B. azotoformans houses only one gene encoding a diheme cytochrome $c$ lipoprotein (BAZO_12419) that consequently might serve nitrite reduction by NirK in this organism.

\section{GENE INVENTORY OF $\boldsymbol{B}$. bataviensis}

B. bataviensis is capable of denitrification, albeit not to $\mathrm{N}_{2}$ but with the stoichiometric production of $\mathrm{N}_{2} \mathrm{O}$ from nitrate [(Verbaendert et al., 2011); Verbaendert et al., unpublished data]. This presumes the presence of the complete denitrification pathway lacking nitrous oxide reductase (NosZ). A first glance at the genome of $B$. bataviensis shows this to be the case. NosZ and its accessory proteins are absent, but the gene inventory for reduction of nitrate to $\mathrm{N}_{2} \mathrm{O}$ is available (Table 3 ). The more close inspection reveals a more complicated situation with sets of truncated or degenerated (pseudo)genes that are difficult to reconcile with full functionality of their gene products. In addition, we note quite interesting differences in the denitrification potentials between B. bataviensis and B. azotoformans.

For cytoplasmic dissimilatory nitrate reduction to nitrite, the genome of $B$. bataviensis contains one narGHJI gene cluster (BABA_18582-18597) with two linked NarK copies (BABA_18532, BABA_18537) in close vicinity (Figure 1A). The NarG, $\mathrm{H}$, J, and I proteins display all conserved features, indicating that NAR is the active NAR in B. bataviensis. This has to be the case since the organism is devoid of the alternative, periplasmic NAR system (NAP). Indeed, none of the nap genes are found in the genome, except a putative napH (BABA_14547). Its gene product (153 aa) is significantly shorter than $\mathrm{NapH}(\sim 300 \mathrm{AA})$ with an established function (Simon et al., 2003; Kern and Simon, 2008), thereby lacking all cysteines for the binding of iron sulfur clusters. Rather, InterProScan suggests BABA_14547 to be an FMN-binding protein.

For dissimilatory reduction of nitrite to NO, again only one candidate is present, a nirK gene that is designated as a pseudogene (BABA_p06582) by the presence of an apparent interspersing stop codon. However, by the correction for a single non-sense mutation (A-C at position 38028 of contig 42), the DNA sequence translates into an amino acid sequence that is $79.8 \%$ identical to NirK from B. azotoformans, differing only three amino acids in length. Moreover, by this substitution all features would be conserved that are related with the binding of the catalytic copper atoms and with the characteristic secondary structural elements of NirK2 family proteins (see above). Again bearing in mind that B. bataviensis is capable of nitrite reduction to NO, we anticipate that this pseudogene, caused by a single non-sense mutation, is probably the result of a sequencing artifact (although base calling was unambiguous). Proteome analysis should confirm this expectation. Like B. azotoformans, B. bataviensis is proposed to carry out also dissimilatory nitrate reduction to ammonia (Table 3 ). The nrfHA gene products (BAZO_17652-17657) meet all criteria described above for functionality (see Figure A1). The question is under which conditions the genes are expressed, taking into account that during standard denitrifying growth nitrate is quantitatively reduced to $\mathrm{N}_{2} \mathrm{O}$.

Contrary to $B$. azotoformans, B. bataviensis seems to have the genetic potential for assimilatory nitrate and nitrite reduction to ammonium. The gene inventory is made up by nas $C$ (BABA_16882) and nirDB (nasGB) (BABA_00910-00915) coding for assimilatory nitrate and nitrite reductase, respectively. Mechanistically, the process could be somewhat different from the one investigated thus far. In many microorganims, nas $C$ and nirDB (nas $G B)$ are localized on the same operon together with NarK-type transporters and regulatory proteins (Luque-Almagro et al., 2011). In $P$. denitrificans NasC and NasGB presumably function as one protein complex (Gates et al., 2011). Herein, NasB (NirB) binds NADH that serves as the reductant for both the six-electron reduction of nitrite to ammonia (by NasB) and the two-electron reduction of nitrate to nitrite (by NasC). The Rieske-type $2 \mathrm{Fe}-2 \mathrm{~S}$ protein $\mathrm{NasG}$ (NirD) intermediates electron transfer between both catalytic subunits. In $B$. bataviensis nas $C$ and nirBD are found in different parts of the genome and are not linked to NarK-type transporters. We note, however, the presence in the nirBD cluster of three genes (BABA_00890-00905) encoding key enzymes for the synthesis of sirohydrochlorin, the prosthetic group of NirB. NasC and NirB are highly similar to the respective proteins of which the function has been established, albeit with a notable difference. NasC (729 AA) from $B$. bataviensis is shorter than the protein from, for instance, $P$. denitrificans (870 AA) and it lacks at its C-terminal part a number of cysteines that might bind an iron-sulfur cluster. However, this difference is shared with many other Gram-positive microorganisms. Although B. bataviensis NirD is $44-57 \%$ identical to NirDs from other Bacillus-related species, there is one important distinction: in the former two key amino acids (cysteine, histidine) are substituted that are involved in the binding of the $2 \mathrm{Fe}-2 \mathrm{~S}$ cluster. In contrast, nas $C$ is linked with two genes coding for a hybrid iron sulfur protein (HCP) (BABA_16877) and for another Rieske-type 2Fe-2S protein (BABA_16872). The particular properties are consistently shared with other species, like Bacillus sp. $1 \mathrm{NLA3E}$, suggesting an alternative, yet functional assimilatory nitrate/nitrite reductase system in B. bataviensis. For the uptake of nitrate, the genome of $B$. bataviensis contains four narK copies, unlike B. azotoformans that has only one. Two of these (NarK2, BABA18537; NarK3, BABA_18532) were already encountered in connection with dissimilatory NAR. They belong to the NarK2 family of nitrate:nitrite antiporters, facilitating the uptake of nitrate and the export of toxic nitrite. NarK1 (BABA_15587) and NarK4 (BABA_18532) are affiliated with the NarK1 family of (high-affinity) nitrate:proton symporters, which would make these proteins attractive candidates to serve $\mathrm{N}$-assimilation. In contrast again to $B$. azotoformans, a gene is present in the genome of B. bataviensis (BABA_17227) coding for an AmtB-type of ammonium transporter.

Regarding $\mathrm{NO}$ reduction to $\mathrm{N}_{2} \mathrm{O}$ and the role therein of $\mathrm{HCO}$ proteins, the genome picture is ambiguous. B. bataviensis contains two copies of qnorB and three HCO copies related to cytochrome $c$-dependent $b a_{3}$ oxidase $(c b a A B)$ from Thermus thermophilus (Table 3). One qnorB is a pseudogene (BABA_p08977), with 
two frame shifts, either resulting from actual point mutations or sequencing errors (although base calling was unambiguous). When the gene sequence was altered manually at both positions (changing $\mathrm{T}$ into $\mathrm{C}$ at position contig55_76292 and A into G at position contig55_76206), the resulting amino acid sequence became highly similar to qNorB sequences from Geobacillus and Bacillus strains (AA sequence identity, 79-83\%). However, it still contained a 217-AA deletion near the C-terminus (from position 464 to 760 in $G$. thermodenitrificans numbering; see Figure A2) comprising only 8 out of 14 TMHs and lacking five out of six conserved histidine residues. Also the other qnorB gene (BABA_17212) is truncated. It is devoid of $273 \mathrm{~N}$-terminal and approximately $150 \mathrm{C}$-terminal amino acids, again spanning only 8 TMHs. Thus, it seems that both qNorBs are corrupted and inactive. Sequence analysis addresses two of the three $b a_{3}$-type oxidases (CbaAB) (BABA_00225-00230, BABA_18502-18497) to the alternative NORs (Figures A3, A4). However, subunit II of the latter one (BABA_18497) lacks approximately 30 amino acids at its $\mathrm{C}$-terminus, including the ones involved in binding of $\mathrm{Cu}_{\mathrm{A}}$. In addition, BABA_18502-18497 are not linked to genes coding for the proposed membrane-bound subunit III and for a SenC/SCO1 protein for $\mathrm{Cu}_{\mathrm{A}}$ insertion. These observations would overrule a role for cyt $c$ as an electron donor, although a function as such for quinol is still feasible. Subunits I (BABA_00225) and II (BABA_00230) of the second candidate are 70 and $79 \%$ identical to the respective subunits of BAZO_06399-006394 that has been identified above as $\mathrm{qCu}_{\mathrm{A}} \mathrm{NOR}$ (sNOR) (Figures 2, A3, A4). Furthermore, the $\mathrm{N}$ terminus of subunit II is quite similar to the one determined by Suharti et al. (2004), having only three mismatches. In full agreement with BAZO_06399-06394, the genes of the $B$. bataviensis are linked to ones encoding a small membranebound polypeptide ( 46 amino acids), another membrane protein (BABA_00215) with $6 \mathrm{TMHs}$ and a SenC/SCO1-type protein (BABA_00220) (Table 3; Figure 2). Unlike BAZO_06399-006394 and all its other relatives, the $B$. bataviensis gene cluster is associated with a gene coding for heme o synthetase (ctaB; BABA_00235). This might imply that the particular B. bataviensis $\mathrm{HCO}$ contains cyt $o_{3}$ at its catalytic side. Nevertheless, the striking resemblance regarding amino acid sequences and the organization of the gene cluster highly suggest BABA_00225-00230 and its associated small membrane subunit to be a menaquinol/cyt $c$-dependent NOR.

The third $b a_{3}$-type (CbaAB) HCO (BABA_08951-08956) is most likely an oxidase, as deduced from its amino acid sequence having the crosslinking tyrosine (Figure A3). It is one of the four oxidases that are detected in the genome. Like in B. azotoformans, oxygen respiration may be mediated by quinoldependent dependent $a a_{3}-600$ oxidase encoded by the qoxBACD genes (BABA_05106-05091) and by cyt $c$-dependent $c a a_{3}$ oxidase (CtaCDEF). In agreement with other organisms, structural genes form part of a larger cluster (ctaABCDEFG) (BABA_1614716177) that includes the $c t a A$ and $c t a B$ genes encoding cyt $a$ and cyt $o$ biosynthesis proteins. A sequence comparison of the gene products just mentioned with those of verified proteins indicates $a a_{3}-600$ oxidase and cyt $c$-dependent $c a a_{3}$ oxidase to be functional (data not shown). Besides these three, we find conserved genes encoding the alternative quinol-dependent cytochrome $b d$ oxidase (CydAB, BABA_01890-01895). CydAB is an oxidase that is found in many microorganisms and that, because of its high affinity for oxygen, (Borisov et al., 2011) is expressed under $\mathrm{O}_{2}$ limitation. B. azotoformans does not contain this oxidase. By the availability of the four different oxidases, B. bataviensis would have the potential to aerobically respire under a wide range of oxygen concentrations. However, the organism seems to be more limited in nitrate respiration as compared to B. azotoformans.

\section{CONCLUDING REMARKS}

Above, we made a comprehensive analysis of the functional denitrification gene inventory of two Bacillus species. Our results are schematically presented in Figure 4. Our exploration came with quite some surprises, we detected potential new enzymes, supported previous suggestions and raised interesting questions that need experimental answers, which we briefly would like to summarize.

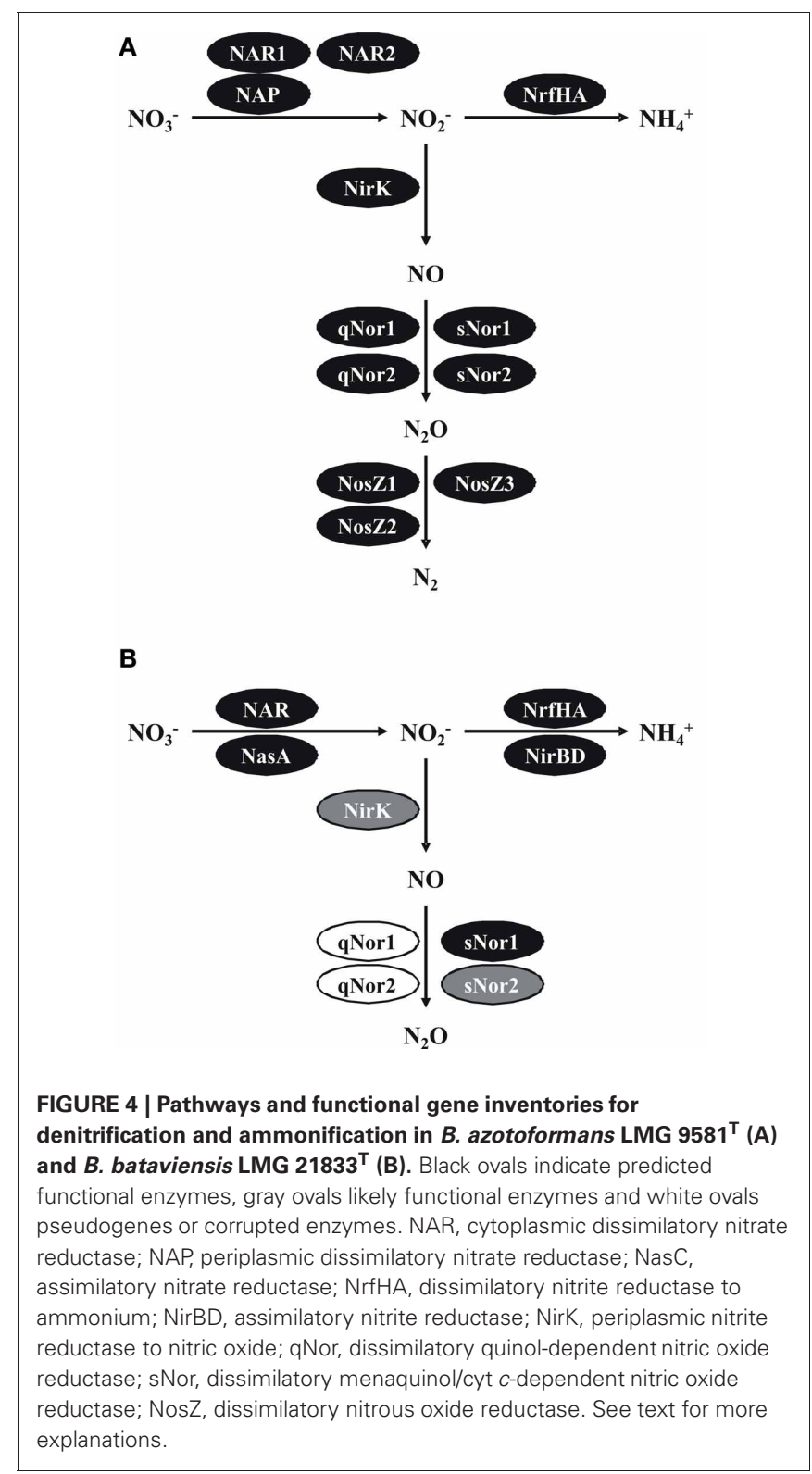


A first surprise was that B. azotoformans, a well-known denitrifier, and B. bataviensis that is less well understood in this respect, are both capable of denitrification and dissimilatory ammonification (DNRA). Especially, B. azotoformans that makes $\mathrm{N}_{2}$ as the end product of nitrate denitrification has a large arsenal of apparently redundant enzymes, but that most likely would enable the organism to thrive under highly variable environmental conditions. The $\mathrm{N}_{2} \mathrm{O}$-producing $B$. bataviensis is much more restricted in this. We note the presence of various pseudogenes that could be relicts of earlier times or situations in which this microorganism could be more dependent on anaerobic nitrate respiration. Striking is the way both Bacillus species took advantage of the opportunities of heme copper oxidases for $\mathrm{NO}$ and $\mathrm{O}_{2}$ reduction. Our analysis permitted the identification of the genes coding for bi-functional $\mathrm{qCu}_{\mathrm{A}} \mathrm{NOR}$ purified and characterized before Suharti et al. (2001, 2004). Yet, we could detect other related novel enzymes that either reduce $\mathrm{NO}$ or $\mathrm{O}_{2}$, but that still need to be validated by biochemical research.

Gram-positive microorganisms typically have limited space in their periplasm, which might pose specific demands on the way denitrification processes are structured in the periplasm. Suharti and de Vries (2005) already noticed that virtually all denitrifying partial reactions in B. azotoformans strain NCCB 10003 were associated with the cell membrane. Our genome analyses support their observations. All enzymes appear to be membranebound, either by TMHs at catalytic enzymes themselves, through association with membrane-bound partners or by covalent binding to lipids (NirK, NosZ). Membrane association most likely requires specific structural and architectural adaptations that are

\section{REFERENCES}

Altschul, S. F., Madden, T. L., Schäffer, A. A., Zhang, J., Zhang, Z., Miller, W., et al. (1997). Gapped BLAST and PSI-BLAST: a new generation of protein database search programs. Nucleic Acids Res. 25, 3389-3402.

Arnoux, P., Sabaty, M., Alric, J., Frangioni, B., Guigliarelli, B., Adriano, J.-M., et al. (2003). Structural and redox plasticity in the heterodimeric periplasmic nitrate reductase. Nat. Struct. Biol. 10, 928-934.

Azarkina, N., Siletsky, S., Borisov, V., Von Wachenfeldt, C., Hederstedt, L., and Konstantinov, A. (1999). A cytochrome bb'-type quinol oxidase in Bacillus subtilis strain 168. J. Biol. Chem. 274, 32810-32817.

Aziz, R. K., Bartels, D., Best, A. A., Dejongh, M., Disz, T., Edwards, R. A., et al. (2008). The RAST server: rapid annotations using subsystems technology. BMC Genomics 9:75. doi: 10.1186/1471-2164-9-75

Bamford, V., Angove, H., Seward, H., Thomson, A., Cole, J., Jn, B., et al. (2002). Structure and spectroscopy of the periplasmic cytochrome $c$ nitrite reductase from Escherichia coli. Biochemistry 41, 2921-2931.

Bendtsen, J. D., Jensen, L. J., Blom, N., Heijne, G. V., and Brunak, S. (2004). Feature based prediction of non-classical and leaderless protein secretion. Protein Eng. Des. Sel. 17, 349-356.

Bendtsen, J. D., Nielsen, H., Widdick, D., Palmer, T., and Brunak, S. (2005). Prediction of twin-arginine signal peptides. BMC Bioinformatics 6:167. doi: 10.1186/1471-2105-6167

Bengtsson, J., Rivolta, C., Hederstedt, L., and Karamata, D. (1999). Bacillus subtilis contains two small c-type cytochromes with homologous heme domains but different types of membrane anchors. J. Biol. Chem. 274, 26179-21684.

Bergaust, L., Mao, Y., Bakken, L. R., and Frostegård, A. (2010). Denitrification response patterns during the transition to anoxic respiration and posttranscriptional effects of suboptimal $\mathrm{pH}$ on nitrogen oxide reductase in Paracoccus denitrificans. Appl. Environ. Microbiol. 76, 6387-6396. reflected in amino acid sequences. In agreement herewith, we note that the denitrification enzymes discussed often form part of (sub)families that are specific for Gram-positive microorganisms. Another aspect that relates to the membrane-bound character is energy metabolism. As pointed out again by De Vries and his coworkers (Suharti et al., 2004; Suharti and de Vries, 2005), all reactions tested used menaquinol as the reductant. Our analyses confirm these findings. However, also cyt $c$ could be utilized as the reductant. This branched electron transfer adds to the metabolic flexibility. The use of (mena)quinol may allow reactions to proceed at high rates, also under conditions of substrate limitation. The use of reduced cytochrome(s) produced through quinol oxidation by the $b c_{1} / b_{6} f$ complex is energetically more favorable.

All in all, our analyses suggest an astonishing versatility in denitrification opportunities, especially for B. azotoformans. The important question is, if and under which environmental conditions the different (partial) processes are expressed. An answer to this needs experimental research.

\section{ACKNOWLEDGMENTS}

This work was supported by the Flemish Fund for Scientific Research (FWO11/KAN/043 and FWO11/PDO/084). We would like to thank H. Op den Camp, K. Ji, and J. van de Vossenberg form the Department of Microbiology of the Radboud University Nijmegen for their helpful suggestions for initial genome assembly and annotation. We would also like to thank the reviewers for their detailed and constructive comments on earlier versions of the manuscript.
Bertero, M., Rothery, R., Boroumand, N., Palak, M., Blasco, F., Ginet, N., et al. (2005). Structural and biochemical characterization of a quinol binding site of Escherichia coli nitrate reductase A. J. Biol. Chem. 280, 14836-14843.

Bertero, M., Rothery, R., Palak, M., Hou, C., Lim, D., Blasco, F., et al. (2003). Insights into the respiratory electron transfer pathway from the structure of nitrate reductase A. Nat. Struct. Biol. 10, 681-687.

Bleakley, B. H., and Tiedje, J. M. (1982). Nitrous oxide production by organisms other than nitrifiers or denitrifiers. Appl. Environ. Microbiol. 44, 1342-1348.

Borisov, V., Gennis, R., Hemp, J., and Verkhovsky, M. (2011). The cytochrome bd respiratory oxygen reductases. Biochim. Biophys. Acta 1807, 1398-1413.

Borodovsky, M., and McIninch, J. (1993). GeneMark: parallel gene recognition for both DNA strands. Comput. Chem. 17, 123-133.

Boulanger, M. J., and Murphy, M. E. P. (2002). Crystal structure of the soluble domain of the major anaerobically induced outer membrane protein (AniA) from pathogenic Neisseria: a new class of copper containing nitrite reductases. J. Mol. Biol. 315, 1111-1127.

Brown, K., Djinovic-Carugo, K., Haltia, T., Cabrito, I., Saraste, M., Moura, J., et al. (2000). Revisiting the catalytic $\mathrm{CuZ}$ cluster of nitrous oxide (N2O) reductase. Evidence of a bridging inorganic sulfur. J. Biol. Chem. 275, 41133-41136.

Cho, C. M.-H., Yan, T., Liu, X., Wu, L., Zhou, J., and Stein, L. Y. (2006). Transcriptome of a Nitrosomonas europaea mutant with a disrupted nitrite reductase gene (nirK). Appl. Environ. Microbiol. 72, 4450-4454.

Coelho, C., González, P. J., Moura, J. J. G., Moura, I., Trincão, J., and Romão, M. J. (2011). The crystal structure of Cupriavidus necator nitrate reductase in oxidized and partially reduced states. J. Mol. Biol. 408, 932-948.

Cunha, C., Macieira, S., Dias, J., Almeida, G., Goncalves, L., Costa, C., et al. (2003). Cytochrome c nitrite reductase from Desulfovibrio desulfuricans ATCC 27774. The relevance of the two calcium sites in the structure of the catalytic 
subunit (NrfA). J. Biol. Chem. 278, 17455-17465.

de Barjac, H., and Bonnefoi, A. (1972). Essai de classification biochimique de 64 "Bacillus" des groupes II et III représentant 11 espèces différentes. Ann. Inst. Pasteur 122, 463-473.

Deeudom, M., Koomey, M., and Moir, J. (2008). Roles of c-type cytochromes in respiration in Neisseria meningitidis. Microbiology 154, 2857-2864.

Denariaz, G., Payne, W. J., and Legall, J. (1989). A halophilic denitrifier, Bacillus halodenitrificans sp. nov. Int. J. Syst. Bacteriol. 39, 145-151.

Denariaz, G., Payne, W. J., and Legall, J. (1991). The denitrifying nitrite reductase of Bacillus halodenitrificans. Biochim. Biophys. Acta 1056, 225-232.

de Vries, S., and Schröder, I. (2002). Comparison between the nitric oxide reductase family and its aerobic relatives, the cytochrome oxidases. Biochem. Soc. Trans. 30, 662-667.

Einsle, O. (2011). Structure and function of formate-dependent cytochrome c nitrite reductase, NrfA. Methods Enzymol. 496, 399-422.

Einsle, O., Messerschmidt, A., Huber, R., Kroneck, P. M. H., and Neese, F. (2002). Mechanism of the sixelectron reduction of nitrite to ammonia by cytochrome $\mathrm{c}$ nitrite reductase. J. Am. Chem. Soc. 124, 11737-11745.

Einsle, O., Stach, P., Messerschmidt, A., Simon, J., Kröger, A., Huber, R., et al. (2000). Cytochrome c nitrite reductase from Wolinella succinogenes. J. Biol. Chem. 275, 39608-39616.

Ellis, M. J., Dodd, F. E., Strange, R. W., Prudêncio, M., Sawers, G., Eady, R. R., et al. (2001). X-ray structure of a blue copper nitrite reductase at high $\mathrm{pH}$ and in copperfree form at 1.9 A resolution. Acta Crystallogr. D Biol. Crystallogr. 57, 1110-1118.

Emanuelsson, O., Brunak, S., Heijne, G. V., and Nielsen, H. (2007). Locating proteins in the cell using TargetP, SignalP and related tools. Nat. Protoc. 2, 953-971.

Falke, D., Schulz, K., Doberenz, C., Beyer, L., Lilie, H., Thiemer, B., et al. (2010). Unexpected oligomeric structure of the FocA formate channel of Escherichia coli: a paradigm for the formate-nitrite transporter family of integral membrane proteins. FEMS Microbiol. Lett. 303, 69-75.

Fee, J., Case, D., and Noodleman, L. (2008). Toward a chemical mechanism of proton pumping by the B-type cytochrome $c$ oxidases: application of density functional theory to cytochrome ba3 of Thermus thermophilus. J. Am. Chem. Soc. 130, 15002-15021.

Feng, L., Wang, W., Cheng, J., Ren, Y., Zhao, G., Gao, C., et al. (2007). Genome and proteome of longchain alkane degrading Geobacillus thermodenitrificans NG80-2 isolated from a deep-subsurface oil reservoir. Proc. Nat. Acad. Sci. U.S.A. 104, 5602-5607.

Fukuda, Y., Tamada, T., Takami, H., Suzuki, S., Inoue, T., and Nojiri, M. (2011). Cloning, expression, purification, crystallization and preliminary X-ray crystallographic study of GK0767, the copper-containing nitrite reductase from Geobacillus kaustophilus. Acta Crystallogr. Sect. F Struct. Biol. Cryst. Commun. 67, 692-695.

Garcia, J.-L. (1977). Etude de la dénitrification chez une bactérie thermophile sporulée. Ann. Microbiol. 128A, 447-458.

Gates, A., Luque-Almagro, V., Goddard, A., Ferguson, S., Roldán, M., and Richardson, D. (2011). A composite biochemical system for bacterial nitrate and nitrite assimilation as exemplified by Paracoccus denitrificans. Biochem. J. 435, 743-753.

González, P. J., Correia, C., Moura, I., Brondino, and Moura, J. J. G. (2006). Bacterial nitrate reductases: molecular and biological aspects of nitrate reduction. J. Inorg. Biochem. 100, 1015-1023.

Heikkilä, M., Honisch, U., Wunsch, P., and Zumft, W. (2001). Role of the Tat transport system in nitrous oxided reductase translocation and cytochrome $c d 1$ biosynthesis in Pseudomonas stutzeri. J. Bacteriol. 183, 1663-1671.

Hemp, J., and Gennis, R. B. (2008). Diversity of the heme-copper superfamily in Archaea: insights from genomics and structural modeling. Results Probl. Cell Differ. 45, 1-31.

Heyndrickx, M., Vauterin, L., Vandamme, P., Kersters, K., and De Vos, P. (1996). Applicability of combined amplified ribosomal DNA restriction analysis (ARDRA) patterns in bacterial phylogeny and taxonomy. J. Microbiol. Meth. 26, 247-259.

Heyrman, J., Vanparys, B., Logan, N. A., Balcaen, A., Rodr $ı$ guez-D $\iota$ az, M., Felske, A., et al. (2004). Bacillus novalis sp. nov., Bacillus vireti sp. nov., Bacillus soli sp. nov., Bacillus bataviensis sp. nov. and Bacillus drentensis sp. nov., from the Drentse A grasslands. Int. J. Syst. Evol. Microbiol. 54, 47-57.

Hino, T., Nagano, S., Sugimoto, H., Tosha, T., and Shiro, Y. (2012). Molecular structure and function of bacterial nitric oxide reductase. Biochim. Biophys. Acta 1817, 680-687.

Ize, B., Coulthurst, S. J., Hatzixanthis, K., Caldelari, I., Buchanan, G., Barclay, E. C., et al. (2009). Remnant signal peptides on nonexported enzymes: implications for the evolution of prokaryotic respiratory chains. Microbiology 155, 3992-4004.

Jacobson, F., Guo, H., Olesen, K., Okvist, M., Neutze, R., and Sjölin, L. (2005). Structures of the oxidized and reduced forms of nitrite reductase from Rhodobacter sphaeroides 2.4.3 at high $\mathrm{pH}$ : changes in the interactions of the type 2 copper. Acta Crystallogr. D Biol. Crystallogr. 61, 1190-1198.

Jepson, B. J. N., Mohan, S., Clarke, T. A., Gates, A. J., Cole, J. A., Butler, C. S., et al. (2007). Spectropotentiometric and structural analysis of the periplasmic nitrate reductase from Escherichia coli. J. Biol. Chem. 282, 6425-6437.

Jetten, M. S. (2008). The microbial nitrogen cycle. Environ. Microbiol. 10, 2903-2909.

Käll, L., Krogh, A., and Sonnhammer, E. L. L. (2004). A combined transmembrane topology and signal peptide prediction method. J. Mol. Biol. 338, 1027-1036.

Kern, M., and Simon, J. (2008). Characterization of the NapGH quinol dehydrogenase complex involved in Wolinella succinogenes nitrate respiration. Mol. Microbiol. 69, 1137-1152.

Kern, M., and Simon, J. (2009). Electron transport chains and bioenergetics of respiratory nitrogen metabolism in Wolinella succinogenes and other Epsilonproteobacteria. Biochim. Biophys. Acta 1787, 646-656.

Kern, M., Volz, J., and Simon, J. (2011). The oxidative and nitrosative stress defence network of Wolinella succinogenes: cytochrome $c$ nitrite reductase mediates the stress response to nitrite, nitric oxide, hydroxylamine and hydrogen peroxide. Environ. Microbiol. 13, 2478-2494.

Kim, S.-H., Harzman, C., Davis, J. K., Hutcheson, R., Broderick, J. B., Marsh, T. L., et al. (2012). Genome sequence of Desulfitobacterium hafniense DCB-2, a Grampositive anaerobe capable of dehalogenation and metal reduction. BMC Microbiol. 12:21. doi 10.1186/1471-2180-12-21

Kraft, B., Strous, M., and Tegetmeyer, H. E. (2011). Microbial nitrate respiration - genes, enzymes and environmental distribution. J. Biotechnol. 155, 104-117.

Kranz, R., Richard-Fogal, C., Taylor, J., and Frawley, E. (2009). Cytochrome c biogenesis: mechanisms for covalent modifications and trafficking of heme and for heme-iron redox control. Microbiol. Mol. Biol. Rev. 73, 510-528.

Krogh, A., Larsson, B., Heijne, G. V., and Sonnhammer, E. L. L. (2001). Predicting transmembrane protein topology with a hidden Markov model: application to complete genomes. J. Mol. Biol. 305, 567-580.

Lam, P., and Kuypers, M. (2011). Microbial nitrogen cycling processes in oxygen minimum zones. Ann. Rev. Mar. Sci. 3, 317-345.

Larkin, M., Blackshields, G., Brown, N., Chenna, R., McGettigan, P. McWilliam, H., et al. (2007). Clustal $\mathrm{W}$ and Clustal $\mathrm{X}$ version 2.0. Bioinformatics 23, 2947-2948.

Lauraeus, M., Haltia, T., Saraste, M., and Wikström, M. (1991). Bacillus subtilis expresses two kinds of haem-A-containing terminal oxidases. Eur. J. Biochem. 197, 699-705.

Liu, B., Zhang, Y., Sage, J., Soltis, S., Doukov, T., Chen, Y., et al. (2012). Structural changes that occur upon photolysis of the $\mathrm{Fe}(\mathrm{II})(\mathrm{a} 3)-\mathrm{CO}$ complex in the cytochrome ba(3)oxidase of Thermus thermophilus: a combined X-ray crystallographic and infrared spectral study demonstrates $\mathrm{CO}$ binding to $\mathrm{Cu}(\mathrm{B})$. Biochim. Biophys. Acta 1817, 658-665.

Liu, X., Gao, C., Zhang, A., Jin, P., Wang, L., and Feng, L. (2008). The nos gene cluster from gram-positive bacterium Geobacillus thermodenitrificans NG80-2 and functional characterization of the recombinant NosZ. FEMS Microbiol. Lett. 289, 46-52.

Lu, S., Suharti, Vries, S. D., and Moënne-Loccoz, P. (2004). Two $\mathrm{CO}$ molecules can bind concomitantly at the diiron site of $\mathrm{NO}$ reductase from Bacillus azotoformans. J. Am. Chem. Soc. 126, 15332-15333.

Lukashin, A., and Borodovsky, M. (1998). GeneMark.hmm: new solutions for gene finding. Nucleic Acids Res. 26, 1107-1115. 
Luque-Almagro, V., Gates, A., Moreno-Vivián, C., Ferguson, S., Richardson, D., and Roldán, M. (2011). Bacterial nitrate assimilation: gene distribution and regulation. Biochem. Soc. Trans. 39, 1838-1843.

Mahne, I., and Tiedje, J. M. (1995). Criteria and methodology for identifying respiratory denitrifiers. Appl. Environ. Microbiol. 61, 1110-1115.

Martínez-Espinosa, R., Cole, J., Richardson, D., and Watmough, N. (2011). Enzymology and ecology of the nitrogen cycle. Biochem. Soc. Trans. 39, 175-178.

Matsumoto, Y., Tosha, T., Pisliakov, A. V., Hino, T., Sugimoto, H., Nagano, S., et al. (2012). Crystal structure of quinol-dependent nitric oxide reductase from Geobacillus stearothermophilus. Nat. Struct. Mol. Biol. 19, 238-246.

Moir, J. W. B., and Wood, N. J. (2001). Nitrate and nitrite transport in bacteria. Cell. Mol. Life Sci. 58, 215-224.

Moriya, Y., Itoh, M., Okuda, S., Yoshizawa, A. C., and Kanehisa, M. (2007). KAAS: an automatic genome annotation and pathway reconstruction server. Nucleic Acids Res. 35, W182-W185.

Najmudin, S., González, P. J., Trincão, J., Coelho, C., Mukhopadhyay, A., Cerqueira, N. M. F. S. A., et al. (2008). Periplasmic nitrate reductase revisited: a sulfur atom completes the sixth coordination of the catalytic molybdenum. J. Biol. Inorg. Chem. 13, 737-753.

Nikaido, K., Noguchi, S., Sakamoto, J., and Sone, N. (1998). The $c b a A B$ genes for bo3-type cytochrome c oxidase in Bacillus stearothermophilus. Biochim. Biophys. Acta 1397, 262-267.

Overton, T. W., Justino, M. C., Li, Y., Baptista, J. M., Melo, A. M. P., Cole, J. A., et al. (2008). Widespread distribution in pathogenic bacteria of di-iron proteins that repair oxidative and nitrosative damage to iron-sulfur centers. J. Bacteriol. 190, 2004-2013.

Paraskevopoulos, K., Antonyuk, S., Sawers, R., Eady, R., and Hasnain, S. (2006). Insight into catalysis of nitrous oxide reductase from high-resolution structures of resting and inhibitor-bound enzyme from Achromobacter cycloclastes. J. Mol. Biol. 362, 55-65.

Peña, A., Busquets, A., Gomila, M., Bosch, R., Nogales, B., GarcíaValdés, E., et al. (2012). Draft genome of Pseudomonas stutzeri strain ZoBell (CCUG 16156), a marine isolate and model organism for denitrification studies. $J$. Bacteriol. 194, 1277-1278.

Petersen, T. N., Brunak, S., Heijne, G. V., and Nielsen, H. (2011). SignalP 4.0 , discriminating signal peptides from transmembrane regions. Nat. Methods 8, 784-786.

Pichinoty, F., de Barjac, H., Mandel, M., and Asselineau, J. (1983). Description of Bacillus azotoformans sp. nov. Int. J. Syst. Bacteriol. 33, 660-662.

Pichinoty, F., Garcia, J. L., Job, C., and Durand, M. (1978). La dénitrification chez Bacillus licheniformis. Can. J. Microbiol. 24, 45-49.

Pitcher, D. G., Saunders, N. A., and Owen, R. J. (1989). Rapid extraction of bacterial genomic DNA with guanidium thiocyanate. Lett. Appl. Microbiol. 8, 151-156.

Pittman, M. S., Elvers, K. T., Lee, L., Jones, M. A., Poole, R. K., Park, S. F., et al. (2007). Growth of Campylobacter jejuni on nitrate and nitrite: electron transport to NapA and $\mathrm{NrfA}$ via $\mathrm{NrfH}$ and distinct roles for NrfA and the globin Cgb in protection against nitrosative stress. Mol. Microbiol. 63, 575-590.

Pomowski, A., Zumft, W. G., Kroneck, P. M. H., and Einsle, O. (2011). $\mathrm{N}_{2} \mathrm{O}$ binding at a [4Cu:2S] coppersulphur cluster in nitrous oxide reductase. Nature 477, 234-238.

Rahman, O., Cummings, S. P., Harrington, D. J., and Sutcliffe, I. C. (2008). Methods for the bioinformatic identification of bacterial lipoproteins encoded in the genomes of Gram-positive bacteria. World J. Microbiol. Biotechnol. 24, 2377-2382.

Rey, M. W., Ramaiya, P., Nelson, B. A., Brody-Karpin, S. D., Zaretsky, E. J., Tang, M., et al. (2004). Complete genome sequence of the industrial bacterium Bacillus licheniformis and comparisons with closely related Bacillus species. Genome Biol. 5, R77.

Richardson, D. (2000). Bacterial respiration: a flexible process for a changing environment. Microbiology 146, 551-571.

Richardson, D., Felgate, H., Watmough, N., Thomson, A., and Baggs, E. (2009). Mitigating release of the potent greenhouse gas $\mathrm{N} 2 \mathrm{O}$ from the nitrogen cycle - could enzymic regulation hold the key? Trends Biotechnol. 27, 388-397.

Richardson, D. J., Berks, B. C., Russell, D. A., Spiro, S., and Taylor, C. J. (2001). Functional, biochemical and genetic diversity of prokaryotic nitrate reductases. Cell. Mol. Life Sci. $58,165-178$.
Rodrigues, M., Oliveira, T., Matias, P., Martins, I., Valente, F., Pereira, I., et al. (2006a). Crystallization and preliminary structure determination of the membrane-bound complex cytochrome c nitrite reductase from Desulfovibrio vulgaris Hildenborough. Acto Crystallogr. Sect. F Struct. Biol. Cryst. Commun. 62, 565-568.

Rodrigues, M. L., Oliveira, T. F., Pereira, I. A. C., and Archer, M. (2006b). X-ray structure of the membrane-bound cytochrome c quinol dehydrogenase $\mathrm{NrfH}$ reveals novel haem coordination. EMBO J. 25, 5951-5960.

Rodrigues, M. L., Scott, K. A., Sansom, M. S. P., Pereira, I. A. C., and Archer, M. (2008). Quinol oxidation by c-type cytochromes: structural characterization of the menaquinol binding site of NrfHA. J. Mol. Biol. 381, 341-350.

Rothery, R. A., Workun, G. J., and Weiner, J. H. (2008). The prokaryotic complex iron-sulfur molybdoenzyme family. Biochim. Biophys. Acta 1778, 1897-1929.

Sakamoto, J., Handa, Y., and Sone, N. (1997). A novel cytochrome $\mathrm{b}(\mathrm{o} / \mathrm{a}) 3$-type oxidase from Bacillus stearothermophilus catalyzes cytochrome c-551 oxidation. J. Biochem. 122, 764-771.

Salzberg, S. L., Delcher, A. L., Kasif, S., and White, O. (1998). Microbial gene identification using interpolated Markov models. Nucleic Acids Res. 26, 544-548.

Sievert, S. M., Scott, K. M., Klotz, M. G., Chain, P. S. G., Hauser, L. J., Hemp, J., et al. (2008). Genome of the epsilonproteobacterial chemolithoautotroph Sulfurimonas denitrificans. Appl. Environ. Microbiol. 74, 1145-1156.

Simon, J. (2002). Enzymology and bioenergetics of respiratory nitrite ammonification. FEMS Microbiol. Rev. 26, 285-309.

Simon, J., Einsle, O., Kroneck, P. M. H., and Zumft, W. G. (2004). The unprecedented nos gene cluster of Wolinella succinogenes encodes a novel respiratory electron transfer pathway to cytochrome $\mathrm{c}$ nitrous oxide reductase. FEBS Lett. 569, 7-12.

Simon, J., Gross, R., Einsle, O., Kroneck, P. M. H., Kröger, A., and Klimmek, O. (2000). A NapC/NirT-type cytochrome c $(\mathrm{NrfH})$ is the mediator between the quinone pool and the cytochrome c nitrite reductase of Wolinella succinogenes. Mol. Microbiol. 35, 686-696.
Simon, J., and Klotz, M. G. (2012). Diversity and evolution of bioenergetic systems involved in microbial nitrogen compound transformations. Biochim. Biophys. Acta Available online at: http://dx.doi.org/ 10.1016/j.bbabio.2012.1007.1005

Simon, J., Sänger, M., Schuster, C., and Gross, R. (2003). Electron transport to periplasmic nitrate reductase (NapA) of Wolinella succinogenes is independent of a NapC protein. Mol. Microbiol. 49, 69-79.

Simon, J., van Spanning, R., and Richardson, D. (2008). The organisation of proton motive and non-proton motive redox loops in prokaryotic respiratory systems. Biochim. Biophys. Acta 1777, 1480-1490

Smirnova, I., Zaslavsky, D., Fee, J., Gennis, R., and Brzezinski, P. (2008). Electron and proton transfer in the ba(3) oxidase from Thermus thermophilus. J. Bioenerg. Biomembr. 40, 281-287.

Smith, M. S. (1983). Nitrous oxide production by Escherichia coli is correlated with nitrate reductase activity. Appl. Environ. Microbiol. 45, 1545-1547.

Soulimane, T., Buse, G., Bourenkov, G., Bartunik, H., Huber, R., and Than, M. (2000). Structure and mechanism of the aberrant $\mathrm{ba}(3)$-cytochrome $\mathrm{c}$ oxidase from Thermus thermophilus. EMBO J. 19, 1766-1776.

Sousa, F., Alves, R., Ribeiro, M., Pereira-Leal, J., Teixeira, M., and Pereira, M. (2012). The superfamily of heme-copper oxygen reductases: types and evolutionary considerations. Biochim. Biophys. Acta 1817, 629-637.

Stein, L. Y., Arp, D. A., Berube, P. M., Chain, P. S. G., Hauser, L., Jetten, M. S. M., et al. (2007). Whole-genome analysis of the ammonia-oxidizing bacterium, Nitrosomonas eutropha C91: implications for niche adaptation. Environ. Microbiol. 9, 2993-3007.

Stein, L. Y. (2011). "Surveying N2Oproducing pathways in bacteria," in Methods in Enzymology: Research on Nitrification and Related Processes, ed M. G. Klotz (San Diego, CA: Elsevier Academic Press), 131-152.

Streminíska, M. A., Felgate, H., Rowley, G., Richardson, D. J., and Baggs, E. M. (2012). Nitrous oxide production in soil isolates of nitrate-ammonifying bacteria. Environ. Microbiol. Rep. 4, 66-71. 
Su, F., Xu, K., Zhao, B., Tai, C., Tao, F., Tang, H., et al. (2011). Genome sequence of the thermophilic strain Bacillus coagulans XZL4, an efficient pentose-utilizing producer of chemicals. J. Bacteriol. 193, 6398-6399.

Suharti, and de Vries, S. (2005). Membrane-bound denitrification in the Gram-positive bacterium Bacillus azotoformans. Biochem. Soc. Trans. 33, 130-133.

Suharti, Heering, H. A., and de Vries, S. (2004). NO reductase from Bacillus azotoformans is a bifunctional enzyme accepting electrons from menaquinol and a specific endogenous membrane-bound cytochrome c551. Biochemistry 43, 13487-13495.

Suharti, Strampaard, M. J. F., Schröder, I., and de Vries, S. (2001). A novel copper A containing menaquinol NO reductase from Bacillus azotoformans. Biochemistry 40, 2632-2639.

Tamura, K., Peterson, D., Peterson, N., Stecher, G., Nei, M., and Kumar, S. (2011). MEGA5, molecular evolutionary genetics analysis using maximum likelihood, evolutionary distance, and maximum parsimony methods. Mol. Biol. Evol. 28, 2731-2739.

Tavares, P., Pereira, A. S., Moura, J. J. G., and Moura, I. (2006). Metalloenzymes of the denitrification pathway. J. Inorg. Biochem. 100, 2087-2100.

Tiedje, J. M. (1988). "Ecology of denitrification and dissimilatory nitrate reduction to ammonium," in Biology of Anaerobic Microorganisms, ed A. Zehnder (New York, NY: John Wiley and Sons).
Tiedje, J., Sexstone, A., Myrold, D., and Ja, R. (1982). Denitrification: ecological niches, competition and survival. Antonie Van Leeuwenhoek 48, 569-583.

Tocheva, E. I., Rosell, F. I., Mauk, A. G., and Murphy, M. E. P. (2004). Side-on copper-nitrosyl coordination by nitrite reductase. Science 304, 867-870.

Tucker, N. P., Autreaux, B. D., Spiro, S., and Dixon, R. (2005). Mechanism of transcriptional regulation by the Escherichia coli nitric oxide sensor NorR. Biochem. Soc. Trans. 34, 191-194.

Urata, K., and Satoh, T. (1991). Enzyme localization and orientation of the active site of dissimilatory nitrite reductase from Bacillus firmus. Arch. Microbiol. 156, 24-27.

van Wonderen, J. H. V., Burlat, B., Richardson, D. J., Cheesman, M. R., and Butt, J. N. (2008). The nitric oxide reductase activity of cytochrome $\mathrm{c}$ nitrite reductase from Escherichia coli. J. Biol. Chem. 283, 9587-9594.

Veith, B., Herzberg, C., Steckel, S., Feesche, J., Maurer, K. H., Ehrenreich, P., et al. (2004). The complete genome sequence of Bacillus licheniformis DSM13, an organism with great industrial potential. J. Mol. Microbiol. Biotechnol. 7, 204-211.

Verbaendert, I., Boon, N., De Vos, P., and Heylen, K. (2011). Denitrification is a common feature among members of the genus Bacillus. Syst. Appl. Microbiol. 34, 385-391.

von Ballmoos, C., Adelroth, P., Gennis, R., and Brzezinski, P. (2012). Proton transfer in ba(3) cytochrome c oxidase from Thermus thermophilus. Biochim. Biophys. Acta 1817, 650-657.

Wang, H., Robert, O., Hall, J., and Gunsalus, P. (2000). The nrfA and nirB nitrite reductase operons in Escherichia coli are expressed differently in response to nitrate than to nitrite. J. Bacteriol. 182, 5813-5822.

Watmough, N., Field, S., Hughes, R., and Richardson, D. (2009). The bacterial respiratory nitric oxide reductase. Biochem. Soc. Trans. 37, 392-399.

Winstedt, L., and von Wachenfeldt, C. (2000). Terminal oxidases of Bacillus subtilis strain 168, one quinol oxidase, cytochrome aa(3) or cytochrome bd, is required for aerobic growth. J. Bacteriol. 182, 6557-6567.

Yu, J., Hederstedt, L., and Piggot, P. (1995). The cytochrome bc complex (menaquinone:cytochrome c reductase) in Bacillus subtilis has a nontraditional subunit organization. J. Bacteriol. 177, 6751-6760.

Yu, J., and Le Brun, N. (1998). Studies of the cytochrome subunits of menaquinone:cytochrome $c$ reductase (bc complex) of Bacillus subtilis. Evidence for the covalent attachment of heme to the cytochrome b subunit. J. Biol. Chem. 273, 8860-8866.

Zdobnov, E. M., and Apweiler, R. (2001). InterProScan - an integration platform for the signaturerecognition methods in InterPro. Bioinformatics 17, 847-848.

Zumft, W., and Kroneck, P. (2007). Respiratory transformation of nitrous oxide (N2O) to dinitrogen by bacteria and archaea. $A d v$. Microb. Physiol. 52, 107-227.

Zumft, W. G. (1997). Cell biology and molecular basis of denitrification. Microbiol. Mol. Biol. Rev. 61, 533-616.

Zumft, W. G. (2005a). Biogenesis of the bacterial respiratory $\mathrm{Cu}, \mathrm{A}, \mathrm{Cu}$ $\mathrm{S}$ enzyme nitrous oxide reductase. J. Mol. Microbiol. Biotechnol. 10, 154-166.

Zumft, W. G. (2005b). Nitric oxide reductases of prokaryotes with emphasis on the respiratory, hemecopper oxidase type. J. Inorg. Biochem. 99, 194-215.

Conflict of Interest Statement: The authors declare that the research was conducted in the absence of any commercial or financial relationships that could be construed as a potential conflict of interest.

Received: 06 April 2012; accepted: 28 September 2012; published online: 18 October 2012.

Citation: Heylen $K$ and Keltjens J (2012) Redundancy and modularity in membrane-associated dissimilatory nitrate reduction in Bacillus. Front Microbio. 3:371. doi: 10.3389/fmicb 2012.00371

This article was submitted to Frontiers in Evolutionary and Genomic Microbiology, a specialty of Frontiers in Microbiology.

Copyright (c) 2012 Heylen and Keltjens. This is an open-access article distributed under the terms of the Creative Commons Attribution License, which permits use, distribution and reproduction in other forums, provided the original authors and source are credited and subject to any copyright notices concerning any third-party graphics etc. 


\section{APPENDIX}

BAZO 03255

BABA 17657

BS

DV

Dd

BAZO 03255

BABA $^{-} 17657$

BS

DV

Dd

BAZO_03255

BABA_ 17657

BS

Dv

Dd

BAZO_03255

BABA_17657

BS

DV

Dd

BAZO 03255

BABA_17657

BS

Dv

Dd

BAZO 03255

BABA_ 17657

BS

DV

Dd

BAZO_03255

BABA_ 17657

BS

Dv

Dd

BAZO_03255

$\mathrm{BABA}^{-} 17657$

BS

Dv

Dd

BAZO_03255

BABA_17657

BS

Dv

Dd

BAZO 03255

BABA_17657

BS

DV

Dd
MEYNMNS LKRALLLAVVAI FALA IMAACG-AKDTKNGSASEPIDTGLPADTISNEAFKDL 59

----MGRFRYGAYLFLLAL--MLIITGCGNDSSDKTATAAGKKTTGLSADEISNEAFKDI 54

----MKQVRS SRYLL I LMMI FS I GLAACS---GEEESQA GTTDTTS I PPDE IVNTAFKDE 53

------------------AGCS---DVSTELKTPVYKTKLTAEEIRNSAFKPE 32

----MNKRIVTTALALATLLGVALLSGCQ---DVSTELKAPKYKTGIAETETKMSAFKGQ 53

FPLQYESFNAT-KDMSDTKYGGSVPTSKFD--------QSKEPLLPILFNGYGFALEYN 109 FPLQYNSYKKN-EKMEDTKYGGSVKRSKYD---------PDKEPLLPILENGYGFATEYN 104 FPLHYESYLKN-AEKSNP------PGSKFV---------TDIEPNLPMLFHNYGFMLEYN 97 FPKQYASYERNDETTVMTEYKGSVPFNKNDNVNPLPEGYRHAQPYLKNLWLGYPFMYEYR 92 FPQQYAS YMKNNEDR IMTDYKGSVPYHKNDNVNPLPKGFKHAQPYLKNLWLGYPFMYEYN 113

EDRGHVYANEDIEKIARINDKSFG-------SCLTCKSTAVPQLLKEENMGDKYWGANER 162 EDRGHTYALEDIRNVKRITDKSVG-------SCYTCKSTAVPKMIEE--MGDSYWGANFN 155 ETRGHAYAVEDVINIARINDNSIG-------SCMTCKSTAVPALLDE--MGDDYWGANER 148 EARGHTYAIQDFLHI DRINRYAE--KGGLPATCWNCKTPKMMEWVKE--SGDGFWAKDVN 148 ETRGHTYAIDDFLNI DRINRFAADGKGNLPATCWNCKTPKMMEWVSQ--YGDKFWSMDVN 171

AEVLPA-------AK-----EMGHSPI GCSDCHDPQTMELRVTRPSFAKAMESQGIDISN 210 KDIWPK------GE-----AMGHSPIGCSDCHDPKTMDLRVTRPSLFKALKAKGVDVSN 203 DEIVPRTLELGAGGESEDLGEFGHMSIGCSDCHDPATMELRITRPSFTNAMERRGIDVTE 208 EFR-----------DK I DMKDHTI GCATCHDPQTME LRITSVPLTDYLVSQGKDPKK 194 EFRA-K---------DKINAHDETI GCANCHDPATME LRLYSEPLKDWLKRSGKDWQK 219

PTKNQMRTYVCAQCHVEYYFEPE----KKEVVFPWANGFKPEEMYEYYETVAKDQ----- 261 PTKNEMRSYVCGQCHDEYYFAAN----NSEVTYPWTKGFKPEEMYEYYNTIAKEN----- 254 ASKNEMRSYVCAQCHVEYYFEPE----NQKVTFPWDNGLKPEDMFEY FENQAKDQ----- 259 LPRNEMRALVCGQCHVEYYFNGPTMGVNKKPVFPWAEGF DPADMYRYYDKHGDLQVKGEE 254 MSRNEKRTLVCAQCHVEYYFTHKDNGPAAKPVFPWDNGFNPEDMYQYYKGHGAKGPDGKP 279

\begin{abstract}
GFKSDWQHNISGAPMLKAQHPEFETVSTGTHGKNGVSCADCHMPYERSDGKKKVSSHNWT 321 GFEKDWVSNISGAPMLKAQHPEFETHLSGTHGKANVSCADCHMPYERVDGKRKITSHWWT 314 NFDYDWVHSISGAPMIKAQHPEFEMWSYGPHGEAGVSCADCHMPYERTDGAKKVTSHHWT 319 GKFADWTHPASKTPMIKAQHPEYETWINGTHGAAGVTCADCHMSYTRSDDKKKISSHWWT 314 GPFVDWVHAASKVPMIKMQHPEYETFQDGPHGAAGVSCADCHMQYVR-EDGKKISSHWMT 338
\end{abstract}

SPLKNIEA-SCRTCHADKTAEELKNNVESIQDTHKDALDKAEE ISVSSHYYVNKMITAKA 380 SPLKTMQT-SCGQCHGDRDLDKLKDRVYEIQDANVKGLHDAQDISTSAHYYVNRMITSGV 373 SPMDNMQN-TCLNCHSDKTEKQMRDRVDAIQDRHIEAMHETQWHSVRAHYFVNRMITAGA 378 SPMKDPEMRACRQCHSDKTPDYLKSRVLFTQKRTFDLLLAAQEVSVKAHEAVRLANEYQG 374 SPMKDPEMRACRQCHADKTGEYLRQRVLYTQQKTFDQLLKAQEMSVKAHEAVRLANAYEG 398

PAAK-----IAEAQELVRKAQWFWDIIAAENSTGFHNPQGAMDSLKMSSEYSSEAIILAT 435 SADK-----IKDAQE FVRRGQWFWDIIAAENSSGFHNPQGSMDSLRISIEQSNKAIRLAT 428 DEEK-----IEEAQYYIRKGQWFWDI IAAENSDGFHNPQGGADSMRTSSDASNKAIEIAV 433 AKAAGYDDLMI QAREMVRKGQFFWDYVSAENSVGFHNPAKALDTLAQSQQFSQKA IDLAM 434 HRAANYEALMAEAREMVRKGQLFWDYVSAENSVGFHNPAKALDTLMT SMECSQKAVDLAT 458

EELVK-----LGVNVDELKAEIEKATKAVLAETDNFKKKDH-ATNTFFPAQQPP-AAPAK 488 EELVK-----KGVNMEELDQEIEKAKKAVADEKVNEKKKDQ-AVNSYFPAQAPVVAAPPK 482 SELAK-----LGEDLDELERQIEETMENVYNEGDPHEKHTH-AVNEYFPNVLELDE---- 483 EATQYGIGKDLSGDIKTIVPPILKMNRKLQQDPEFMKTHKWFQYLPVLPKADQVWDGQKR 494 EATDFGIAPALAGDI KKLVPPILTLSRKLQQDPEFLKQNPWTRLLPALPKAEQVWEGQDR 518

$$
\begin{array}{ll}
\text { K----- } & 489 \\
\text { K----- } & 483 \\
------ & \\
\text { LVSAKQ } & 500 \\
\text { A----- } & 519
\end{array}
$$

FIGURE A1 | Multiple sequence alignment of NrfA from B. azotoformans LMG $9581^{\top}$, B. bataviensis LMG $21833^{\top}$, and other bacteria. Heme-binding motifs are highlighted in red (white lettering), the lysine at the catalytic heme is highlighted in green, active site residues are printed in blue, distal heme-ligating histidines for hemes 2-6 are printed in red [according to Einsle et al. (2000)]. Bs, Bacillus selenitireducens MLS10 (Bsel_1305); Dv, Desulfovibrio vulgaris DP4 (PDB 2J7A); Dd, Desulfovibrio desulfuricans (PDB 10AH_A). PDB, protein database accession number. 

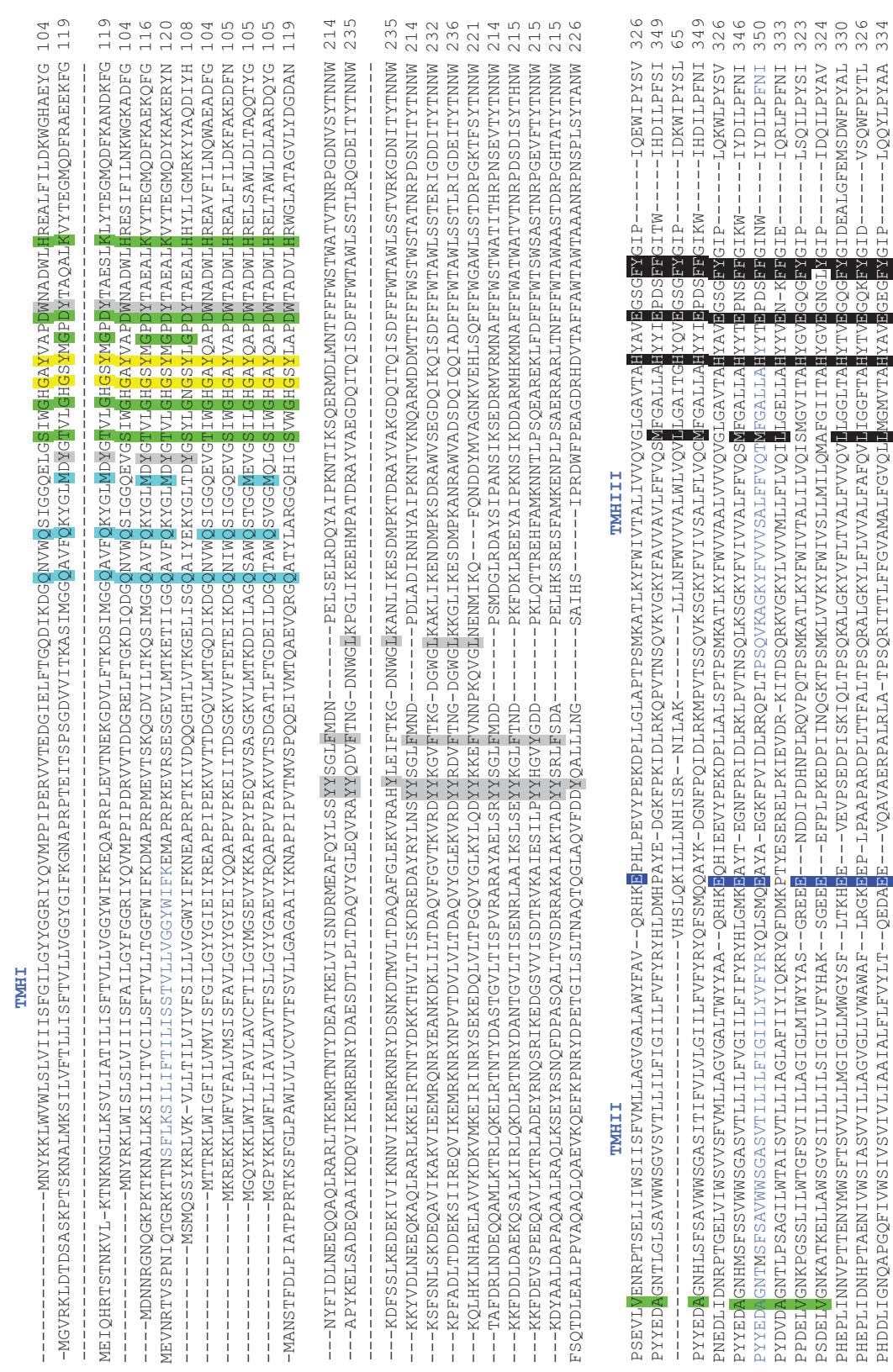

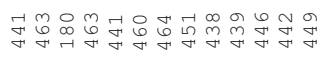

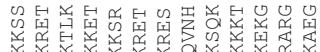

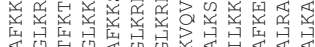

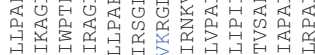

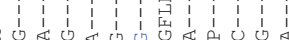

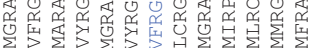

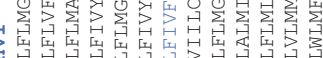

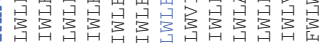

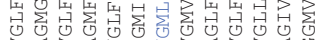

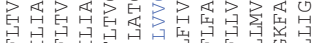

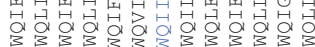

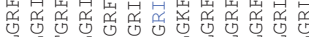

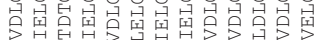

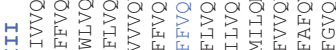

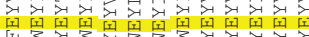

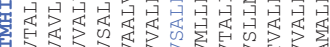

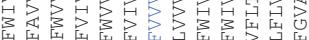

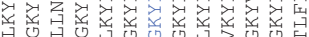

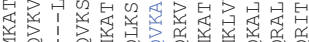

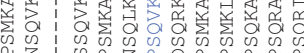

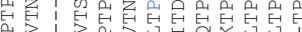

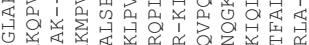

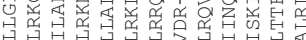

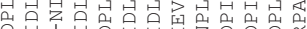

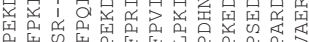

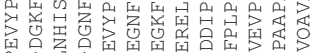

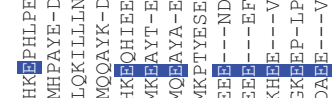

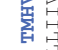

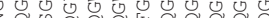

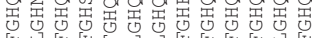

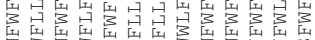

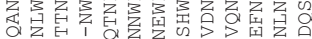

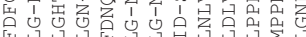

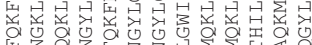

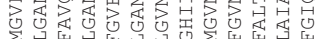

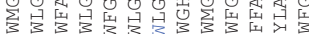

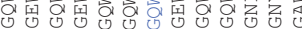

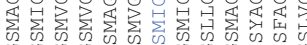

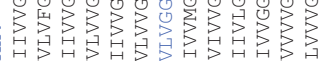

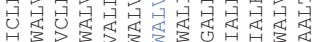

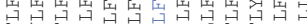

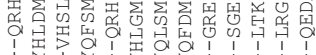

离采

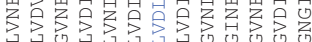

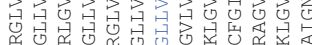

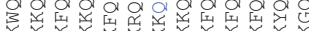

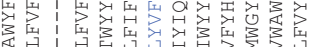

奀出

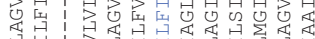

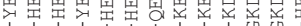

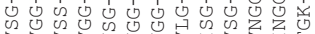

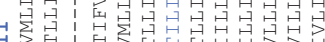

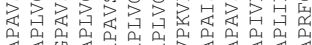

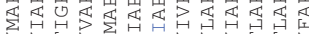

焉

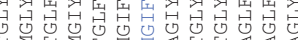

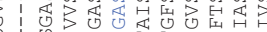

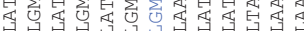

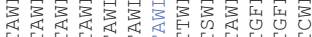

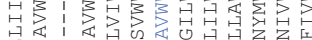

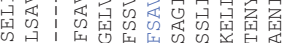

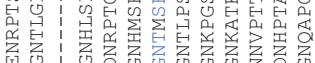

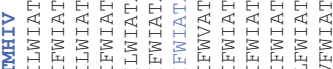

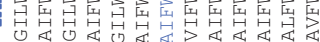

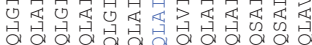

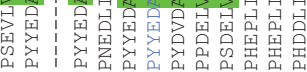

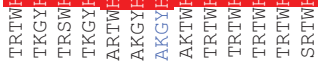

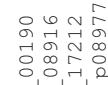

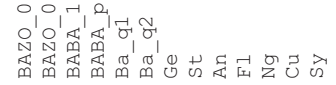

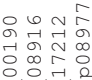

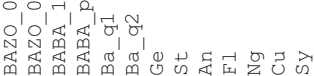

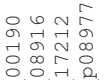

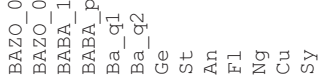




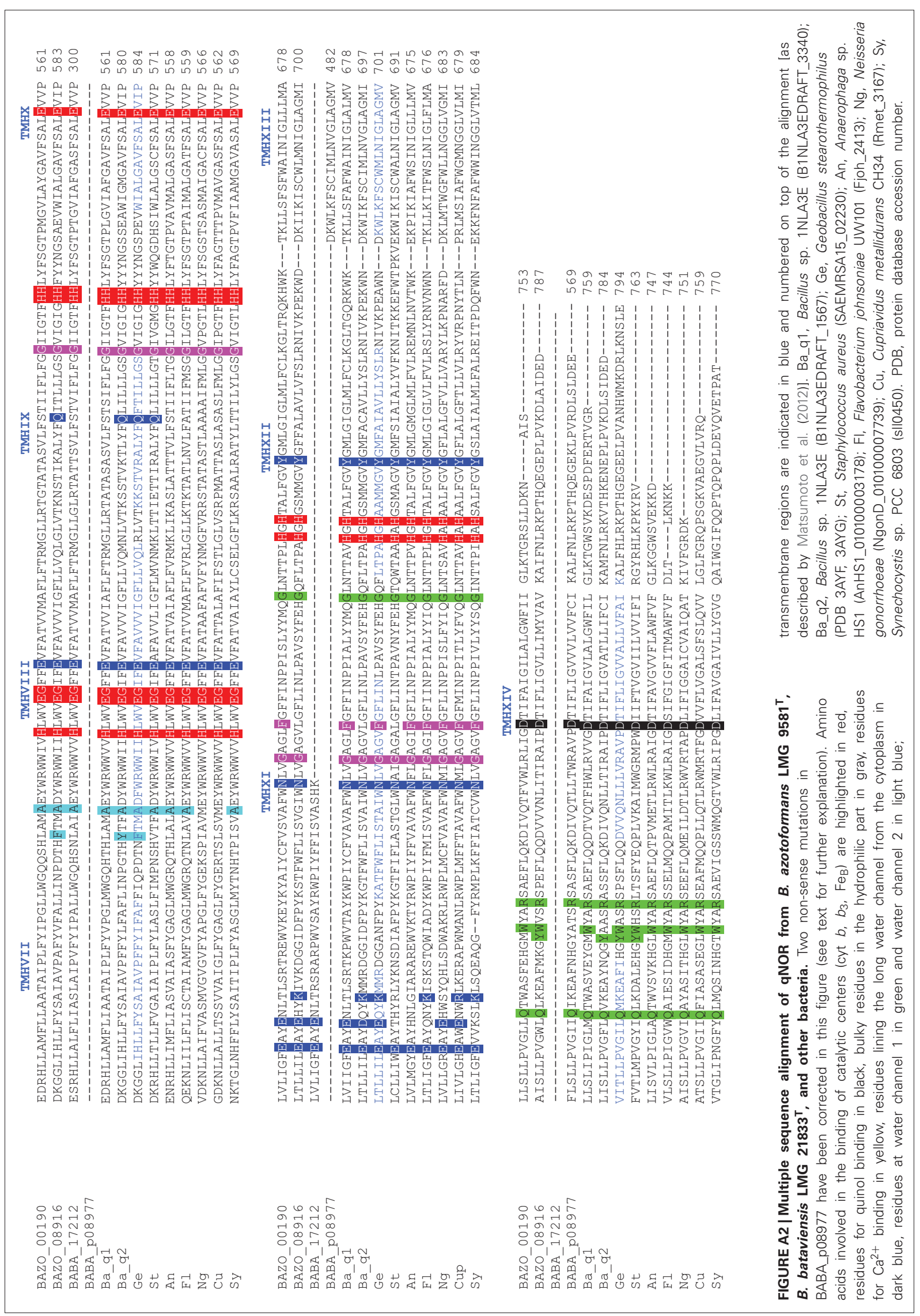


Tthermo_subI GTNG $13 \overline{9} 4$ GTNG ${ }^{-} 1518$ BAZO-04705 BAZO_06399 BAZO- 09851 BAZO_10757 BABA-00225 BABA_08956 BABA_18502

Tthermo_subI GTNG_1394 GTNG $^{-1518}$ BAZO-04705 BAZO-06399 BAZO 09851 BAZO- 10757 BABA_00225 BABA- 08956 BABA_18502

Tthermo subI GTNG_13 $\overline{9} 4$ GTNG $^{-} 1518$ BAZO_04705 BAZO- 06399 BAZO_09851 BAZO 10757 BABA_00225 BABA 08956 BABA_ 18502

Tthermo_subI GTNG $13 \overline{9} 4$ GTNG ${ }^{-} 1518$ BAZO-04705 BAZO_06399 BAZO_09851 BAZO_10757 BABA_00225 BABA_08956 BABA_18502

Tthermo_subI GTNG $13 \overline{9} 4$ GTNG $^{-} 1518$ BAZO-04705 BAZO_06399 BAZO- 09851 BAZO_-10757 BABA-00225 BABA_08956 BABA_ 18502
----------------------YPEKKATLYFLVLGFLALIVGSLFGPFQALNYGN 34 ------------MVQP---LEKVDRRDAKLALAHLFVAF IALGLGGFAGLLQTLVRSG 43 ---------------------MEANVRKMTALYMFVSGIAILLMMVLGLLMLLAQGK 36 ---------------MRPITDTVNSSTRKSVVFPTLLGSVLILLMMVVGLIMLLNQGK 43 MQPTSSTANMSKPSFKERSNQMLGAIPQDAIITKSYLFVAFTAVLLGGLLGLLQGLNRAG 60 ------------MNP---IAS INPKDAKLTMAHFYVAF IS LFLGATAGLLQVLVRSG 42 --------------MKG---VAS IDKRDAKLTMAHLYVAFVALFLGATAGLLQTLVRSG 42 MQTAKSRD------FKDKANKIMGISKEDALLTKSYIFVAFMAILLGGILGLVQGLNRAG 54 ------------MVNTTATKVKVDPRDAKLSMAHF FVAFSALALGGLMGLLQTLVRSG 46

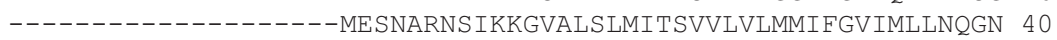

VDAYPLLKRLLPFVQSYYQGLTLHGVLNAIVFTQLFAQAIMVYLPARELN--MRPNMGLM 92 KF------ELPGGISYYTILTTHGVLLGLVLTTFFIIGFQFAAVSRTAGTFTDSTRRVG 96 MIP--------LGQDTFYEMMTAHGTFMVGAAAFAASAVMWYFLR-----QYVRLSFPIF 83 LIT--------ISDGFFYKIMTLHGTGMIGAGALAGTAIMYYFTS-----QYIKLSKAIF 90 LLQ------QMPLGLNYYQILTAHGLLLVVIFSATFVIGYFYAGMSHTLGGLLPKVRKIV 114 KV-------TLPAGIQYYQVLTVHGVLLALVFTTFFIIGFIFATQSKTCGSYTDGERRWG 95 KV-------TLPAGINYYQVLTVHGVLLGLVLTTFFIIGFIIAGQSKVCGTLSAGERRFG 95 LL------ELPSWVNYYQVLTAHGLLLVVVLTAFFTIGYFYAGMSHTLGGLLPKVRTMA 107 KW-------ELPWGIDYYQILTVHGVLMGLVLTTFFIMGFQYAAVSRTTGGHSNAARRTG 99 MVK--------IPAQMFYKVMTIHGTGMIGIAALGGSAIMWYYLS-----KYIHLNHKIF 87

WLSWWMAFIGLVVAALPLLANEATVLYTFYPPIKGHWAFYLGAS--------VFVLST-- 142 WIGFWLMT I GTAMSAFF I LTGQAAVLYTFYAPIQAHAGFYIGLA--------LVVVGS-- 146 VTHFVLFLTGAVMTAISIFVFRFAGAWTFLYPIPAMSAGMWGKTGASLYLIGMLLIGVSF 143 VSNIVLSILGVVMVLIGIFVFDFAAAWTFLYPIPAISGGMWGAAGAVFYLGGMTVLGTGF 150 WTGFWLKIVGTVVVVI PVLMNEASVMYSFYPPMKAHPMFYFGLV--------FVVLGV-- 164 WIGYWMMTVGVAIAATFILLGEASVLYTMYAPMMAHPMHYIGLT--------LVVVGS-- 145 WIGYWMMTIGVAITATFI LLGEGSVLYTMYAPIMAHPLHYTGLT--------LVVVGS-- 145 WIGFGLKMVGFVLAVIPI IMGDASVMYTFYPPMAAAPMFY IGLA--------LIVVGV-- 157 WIGFWIMLLGTLMAATMVLLKEASVLYTFYAPI KAHWIFYLGLT--------FVIVGS-- 149 FANLILSLIGVVMILTAIFGFNFSDGWTFLYPIPSFSAKIYGTTGALLFLFGLLLLGVGY 147

---------WVSIYIVLDLWRRWKAANPGKV--TPLVTYMAVVFWLMWFLASLGLVLEA 190 ---------WVSGFAMFAHYARWRKAHRGQA--SPLLTFMSVTNMALWLICTLGVAATV 194 LLLYLDTSRAIIREYGSLGHGLGWPQILGKVKGYGP PPTVVASTMVS IVNLVSLTVGASV 203 LLFYLDTGRAI IKKYGNLGNALGWP I IFGKTMKEELPPAIVAGTMVTIVNTAALVSGASV 210 ---------WAAAIGAFIQVASWRKNNPGKH--VPIFSFFATGVFILLVGATLMVAVEV 212 ---------WVCGFVVFHRHARWRKENRGQV--TPLLSYMGVMTMIMWLVACLGLATTV 193 ---------WVEGFVVFHRHARWKKENPGQT--TPLLSFMGVATLILWLVACLGLATTV 193 ---------WMCAFGAFIQVANWRKNHKGQH--VPILSYFATGVFVLLFFGSLPVAIEV 205 ---------WIDGAAQIMTYARWRKNNPGQP--SPLLSFMAVINTVMWIVATLGVAATV 197 LVMYFYLAARLIKEYGGLGKSLGWDYIFRGKKGYGPPPAVVATTMVIIANSTGILAGATA 207

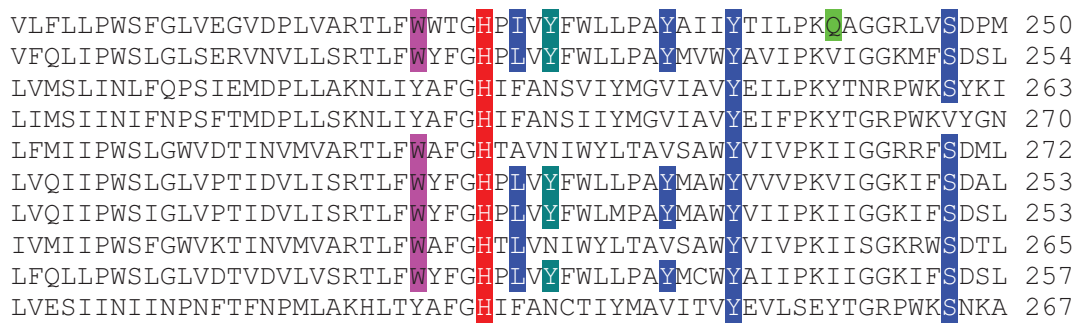


Tthermo subI

GTNG_13 $\overline{9} 4$

GTNG 1518

BAZO_04705

BAZO- 06399

BAZO_09851

BAZO- 10757

BABA_00225

BABA 08956

BABA_ 18502

Thermo subI

GTNG $13 \overline{9} 4$

GTNG ${ }^{-1518}$

BAZO-04705

BAZO- 06399

BAZO-09851

$\mathrm{BAZO}^{-} 10757$

BABA_00225

BABA 08956

BABA_ 18502

Tthermo_subI

GTNG $13 \overline{9} 4$

GTNG ${ }^{-} 1518$

BAZO-04705

BAZO_06399

BAZO_09851

BAZO_10757

BABA-00225

BABA 08956

BABA_18502

Tthermo_subI

GTNG $13 \overline{9} 4$

GTNG ${ }^{-} 1518$

BAZO- 04705

BAZO_06399

BAZO-09851

BAZO 10757

BABA 00225

BABA_08956

BABA_18502

Tthermo subI

GTNG_139̄ 4

GTNG 1518

BAZO_04705

BAZO_06399

BAZO_09851

BAZO_10757

BABA-00225

BABA_08956

BABA_18502

Tthermo subI

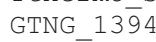

GTNG 1518

BAZO_04705

BAZO- 06399

BAZO_09851

BAZO 10757

BABA_00225

BABA- 08956

BABA_18502
ARLAFLLFLLLSTPVGFHHQFADPGIDPTWKMIHSVITLFVAVPSLMTAFTVAASLEFAG 310 ARLAFI LFLLFS I PVGFHHQLLEPGISPFWKYVQVVLTFMVI IPSLMTAFSMFATFESYG 314 FLIAWNMSTLFTIIVYPHHLLMDFVMPKWMLI IGQVFSY LNGLP--VLVVTAFGALMIVY 321 FLIAWNASTLFTMI IYPHHLLMDFAVPKWML I LGQVLSYANGLP--VLVVTAFGALQI IF 328 TRVVIIALVIMNITGGEHHQI IDPGISEP IKFMHVFMSLAIGFPSLMTAYAMFAVMERTG 332 ARLSFVLFI LFS I PVGFHHQLLEPGIDPFWKYLQVVITFLVVIPSLMTAFALFATFEMRG 313 ARLSFVLFLLFSMPVGFHHQLLEPGIDP FWKYLQVVITYLVVIPSLMTAFSLFATFELRG 313 TRVVI IALVVMNITGGEHHQIVDPGISPSVKFMHVFMSLAIGEPSLMTAWAMFAVFERTA 325 ARLSFI LFLLFS I PVGFHHQLTEPGIDPAWKFFQVIITFMVVIPSLMTAFSLFATFERYG 317 FLIAWNFSTLFTLMIYTHHLLMDFAVPRWMLIIGQVFSYANELP--VMVVTAYGALMIVF 325

RLRGGRGLFGWIRALPWDNPAFVAPVLGLLGFIPGGAGGIVNASFTLDYVVHNTAWVPGH 370 RSQGAKGLFGWLRKLPWGDARFFAPFVGMLFFI PAGTGG I INASHQLNQVVHNTIWVTGH 374 RS----------GIEWDRASSFI-FLSMFGWVAGVIPAIADATIVINHVMHNTKWVPGH 369 RS-----------GIKWDMPSTLF-FMSMFGWVMGVVPA I IDATIAINHVMHNTKWVPGH 376 REKGGKGAFGWFKKLPWGDVRFLAPF I GMAAFAPAGAGGIVQSTNQLDQTVHNTMWIVGH 392 RELGATGLLGWWKKMPWKDARFFAPFMGMLFFAAGGAGGLVNASHQLNQVVHNTIWVTGH 373 RELGATGIFGWWKKLPWKDARFLAPFLGMLLF I PGGAGG IVNASHQMNQVVHNTIWITGH 373 RKQGGKGLIGWYKKMPWGDVRFLAPMIAMIAFIPAGAGGIAQSTNQLDQVVHNTMWIVGH 385 RSKGATGLFGWFKVLPWGDARF IVPFIGMASF I PAGAGG I INASNQMDQVVHNTIWITGH 377 RS---------AVKWDFASSMM-FLAMFGWVAGAVPA I IDATIVVNHVMHNTKWVPGH 373

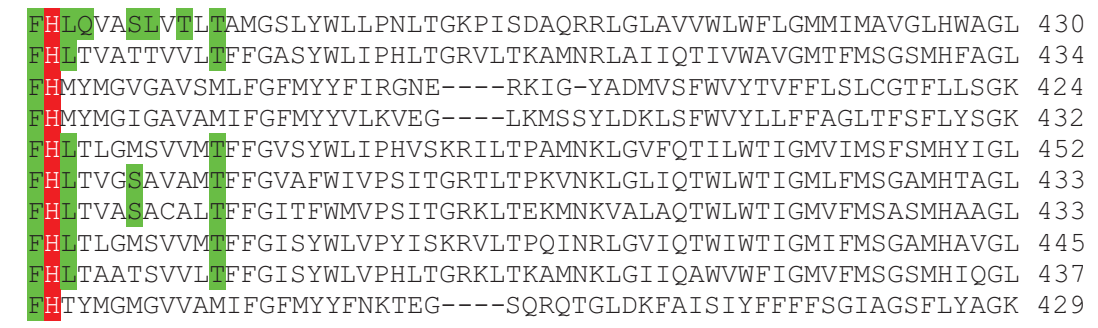

LN-VPRRAYIAQVPDAYPHAAVP--MVFNVLAGIVLLVALLLFIYGLFSVLLSRERKPEL 487 LG-APRRSAFSTYGNSPQALEWIPYQIAQAVGGTILFIGI ILMLVIVINLAFFAPK---- 489 VS-APRRWAVHFP-------EWVPYDRMGAVFAVVIIAAVTVFLYRFF------------ 464

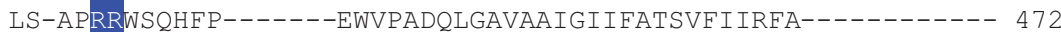
YGGS PRRTSYTTYFDHPMALSWDPWMLAVGIGAVLLFTAVCIQVFAAFNLMFFAPK---- 508 YG-APRRSAFSTYAGNEDTLAWIPYQIAQAVGGTFLFLGALLMVYIFVYLAFYAPK--- 488 FG-APRRSAFSTYAGNEDSLAWIPYQIAQAVGGTILFLGALLMVVIFINLAFFAPK---- 488 LG-SPRRTSFTTYGDNATALSWNPYLLCLAVGGTLLIIGVLLQVYAVINMMFFAPK---- 500 LG-GPRRSAFSTYGGAKQAAEWI PYQIAQAVGGS I LFLGI ILVLI IFVNLAFFAPK---- 492 IS-APRRWAEHLP-------EWTGSDQVGAICGIFVIVAAI IFTTRFF------------ 469

AEAPLPFAEVISGPEDRRLVLAMDRIGFWFAVAAILVVLAYGPTLVQLFGHLNP-VPGWR 546 GETEFPVAEAATPQE--RVVLVFENWKLWIGIVVALILIAYTVPLIDIIQNAPPGSKGYK 547

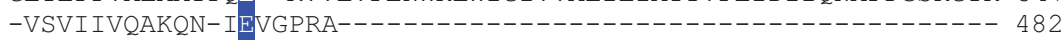

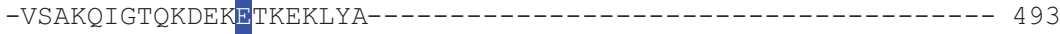
GVTEFPIGEPQSDDE--KTPYWTERWGIWVVLMIITIAMAYTVPLVEMIVNGPPGSPPFK 566 GETEFPVGEVHDQAE--KVPAVFENFKLWVAITFALVLFAYTIPFIDMIQNAPPGSPGYT 546 GEEEFPIGEVHEKAE--KVPAIFDNFKVWIAVTFTLILFAYTIPFIDMIQNAPPGSPGFT 546 GDTEFPIAEEEENAT--KTPYWTERWGMWIVVMLLVVAMAYVIPLSEFIVNAPPGSPPFK 558 EEEEFPVAEAENMGE--KAPMVFENWKLWLGITAALILFAYT I PFIDI IQNAPPGSKGFQ 550 -IGLKNVGKQTEQKSLKSVS------------------------------------ 488
LW---- 548
LW---- 549
$-----$
$------$
TW---- 568
NVIGRQ 552
NVIGRQ 552
TW---- 560
TWSKW- 555
$-----$

FIGURE A3 | Multiple sequence alignment of CbaA from B. azotoformans LMG $9581^{\mathrm{T}}$, B. bataviensis LMG $21833^{\mathrm{T}}$, Geobacillus thermodenitrificans NG80-2 (GTNG_1394; GTNG_1518), and. T. thermophilus (PDB 3EH3). Amino acids involved in the binding of heme $b$, heme $b_{3}$, and $\mathrm{Cu}_{\mathrm{B}} / \mathrm{Fe}_{\mathrm{B}}$ are highlighted in red, residues forming $\mathrm{D}$-water channel in blue, residues forming Q-water channel in green, crosslinking tyrosine in oxidases in dark green, residues related with electron transfer in purple. PDB, protein database accession number. 


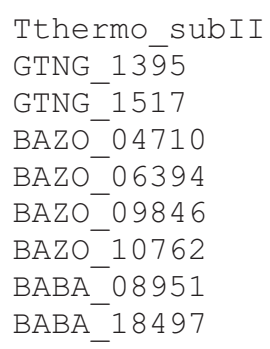

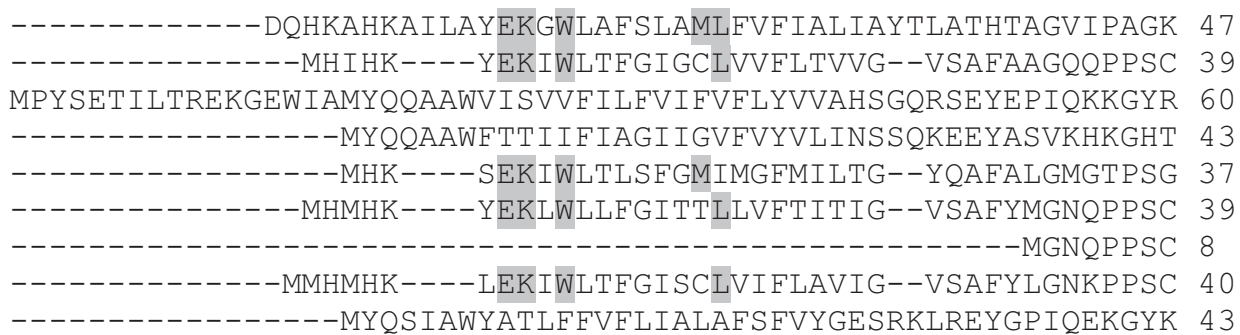

LERVDPTTVRQEGPWA-------DPAQAVVQTGPN-QYTVYVLAFAFGYQP---NPIEVP 96 LTTIDPEKVDTTPPFD-------QPGLVKK--GEN-EYELNIVVAAFSFTP---NAIEIP 86 IRNVWFLVVIAAMGLATFYTLRDLPFE--RPAHAADPTVVQVEARQFGFVL---SRNEFR 115 VQKFYFLGLIVVLGIATTITLQDLPFD--RAKAQENQIEVDATAMQFAFEL---SQNEFK 98 QTTLDPQKVDQTAPFD-------KPGVTQI--GEN-EYEVVMTLQIESFTP---NKLEFP 84 LVTVDPANVDTTAPFD-------QPGLKQV--GDN-QYELIVVASAFNYDVGPEKVIQVP 89 LVTVDPTKLDTTAPFD-------QPGLKQV--GEK-DYELVIVASAFNYDVGPEKVIQVP 58 LTTINPEKVDETKPFD-------KPGLHKVE-GKDWDYELVYVAAAFSYSP---AKVEVP 89 IRKFYFLGLLAVMGFASA ISLSKLPYHNQHVLAKEDGKIVDVTGMQEAWEL---SDENFT 100
FIGURE A4 | Multiple sequence alignment of CbaB from B. azotoformans LMG $9581^{\top}$, B. bataviensis LMG $21833^{\top}$, Geobacillus thermodenitrificans NG80-2 (GTNG_1395; GTNG_1517), and
T. thermophilus (PDB 3EH3). Contact site residues are highlighted in gray, residues for $\mathrm{Cu}_{\mathrm{A}}$-binding in red, and residues for electron transport in pink. PDB, protein database accession number. 


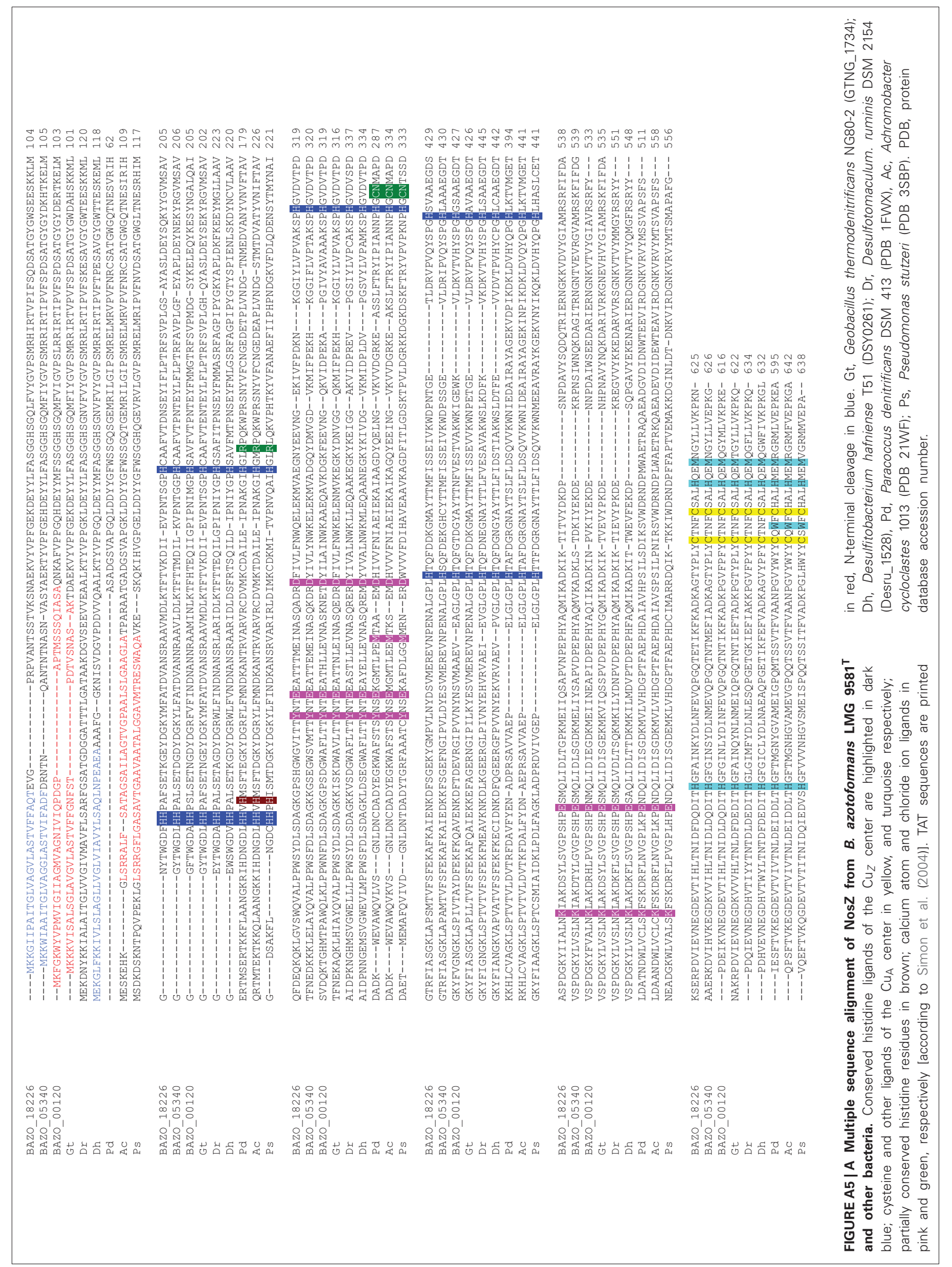

